مجلة جامعة الملك عبدالعزيز: الآداب والعلوم الانسانية، م29ع3 ص ص: 594- 619 (2021م) DOI:10.4197/Art.29-3.21

\title{
طلاب المنح الوافدون بجامعة الإمام محمد بن سعود الإسلامية (دراسة في جغرافية السكان)
}

\author{
علي معيض أحمد محمد القرني

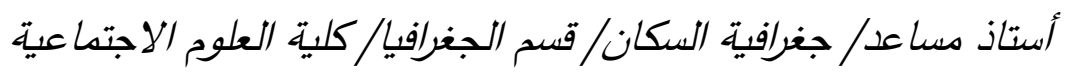 \\ جامعة الإمام محمد بن سعود الإسلادية
}

مستخلص. في الآونة الأخيرة تضاعَف عدد الطلاب الدوليين الدارسين خارج بلادهم؛ مما دعا إلى زيادة الاهتمام

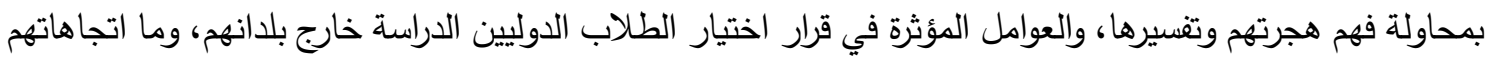

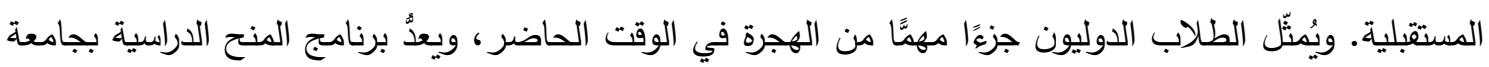

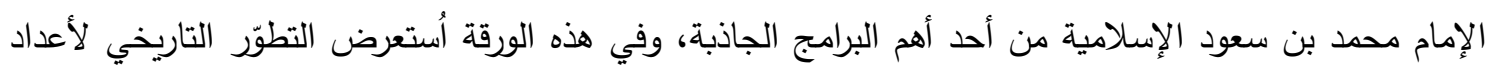

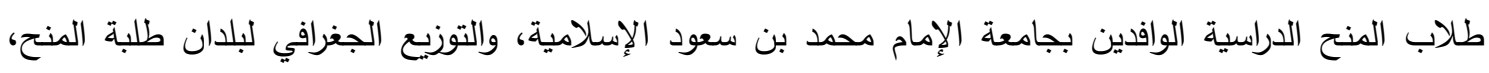

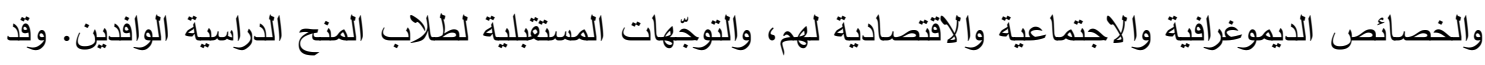

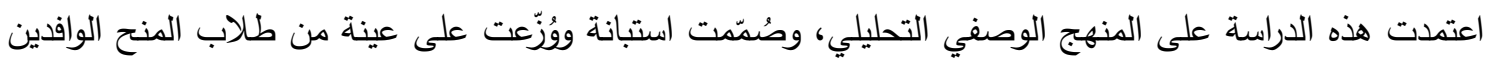
شملت (324) طالبًا.

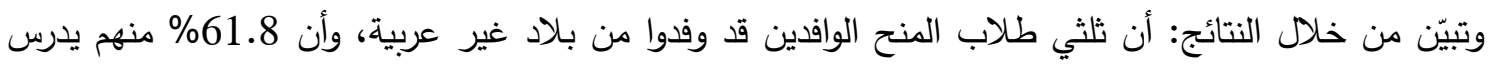

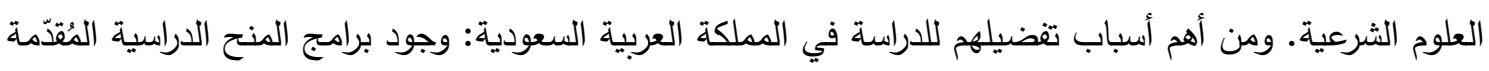

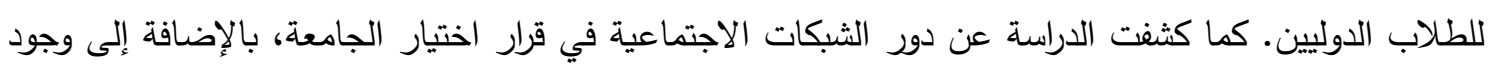

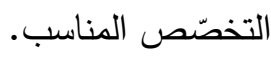
الكلمات المفتاحية: الطلاب الدوليون، طلاب الدنح الدراسية، الهجرة الخارجية، جامعة الإمام محمد بن سعود

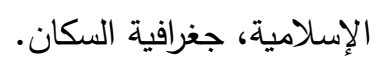

زيادة في حجم الطلاب الدوليين في جميع أنحاء

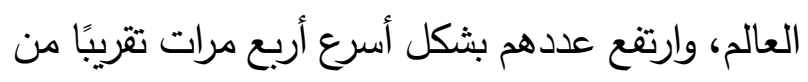
إجمالي الهجرة الدولية، ويُعدّ التعليم من أسباب الهجرة

\section{المقدمة}

تعدُّ هجرة الطلاب من الاتجاهات المعاصرة في الهجرة الدولية في وقتتا الحاضر ، وقد شهدت العقود الماضية الجية 
والاقتصادية والثقافية. ويعدّ الطلاب الدوليون جزءًا مُهِهمًا في الجامعات والكليات اليوم، ومصدرًا مهمَّا للتتوّع والتبادل الثقافي، وأحد مصادر نقل المهارات والخبرات وتبادل المنافع. ويشهد العالم في وقتنا الحاضر زيادة في حجم هجرة الطلاب الدوليين، ويعدُ ولئل

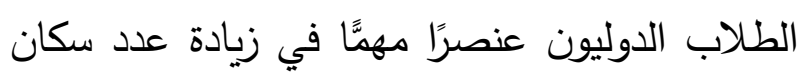

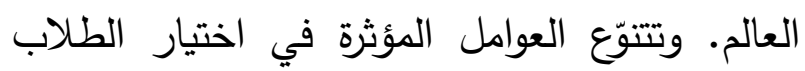
الدوليين لوجهتهم الدراسية، وعلى الرغم من اتجاه غالبيتهم إلى وجهات الدراسة التقليدية، مثل: الولايات

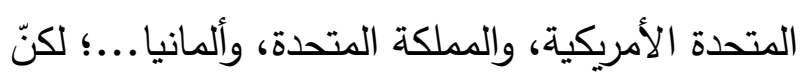
هناك اتجاهًا نحو بعض البلدان النامية بوصفها وجهة ولئة

لهم.

وبدأت الحكومات ومؤسسات التعليم العالي تضع

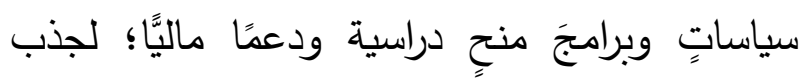
الطلاب الأجانب، وقد ساهدت هذه البرامج والسياسات في توجيه العديد من الطلاب الدوليين إلى جامعات

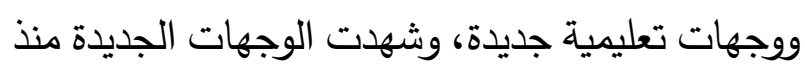
عام 2000م تزايدًا في فرص التحاق الطلبة بها على ونى حساب الوجهات التقليدية، وهذه الوجهات مثل:

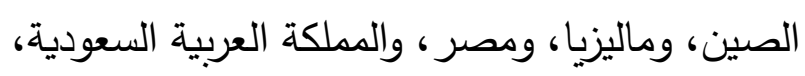
والإمارات العربية المتحدة. وتعدّ المملكة العربية السعودية من ضمن أبرز

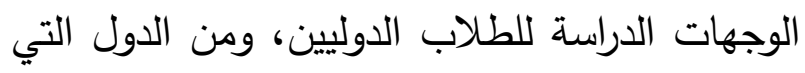
لها برامج وسياسات تستقطبه، ويعود تاريخ البرنامج

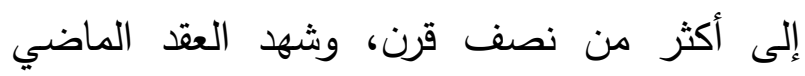
تضاعفت عدد الطلاب الدوليين الملتحقين بالجامعات
الخارجية ودوافعها في وقتنا الحاضر ، حيث يسعى الفرد إلى البحث عن فرص تعليمية، أو البحث عن ودن فرص أفضل من تلك المتوافرة لديه في بلده.

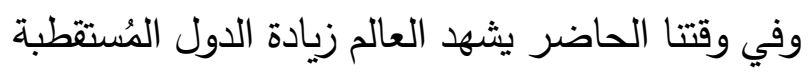

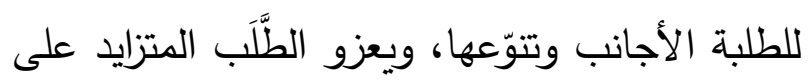

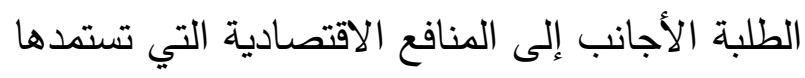

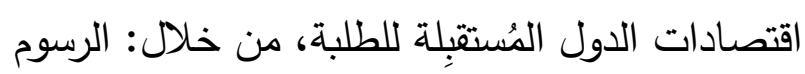

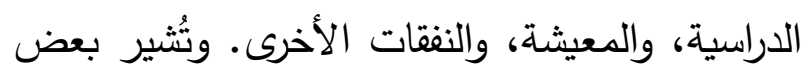

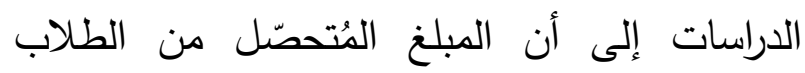
الأجانب كرسوم دراسية كل عام؛ يتجاوز (45) مليار

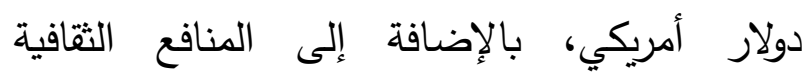
والأكاديمية؛ فالطلبة الأجانب يُمثّلون قوة محرّكة ودافعة لعجلة البحث العلمي إلى الأمام، وعلى سبيل

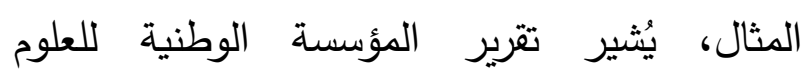
إلى أن (National Science Foundation) الطلاب الأجانب في أميركا ساعدوا بما نسبته 51\% في أبحاث مهمة بالجامعات (p:2.2013.Stuart). وقد ازدادت أعداد الطلبة الملتحقين بالتعليم العالي بالجيات خارج بلادهم إلى أكثر من ثلاثة أضعاف، فمن (1.3)

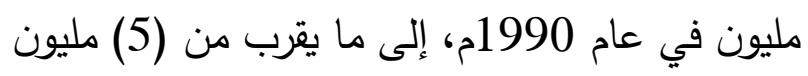

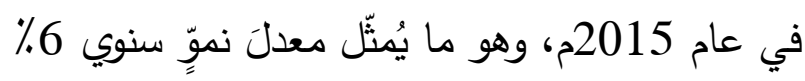
تقريبًا. وهذه زيادة أكبر من الزيادة الإجمالية في مئي

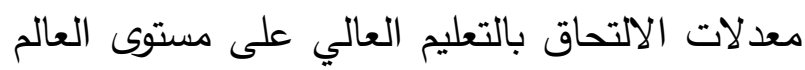

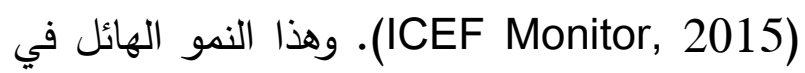
الطلبة الدوليين بجميع أنحاء العالم نتاج مجموعة متنوّعة من العوامل: السياسية والاجتماعية 
وتعدّ جامعة الإمام محمد بن سعود الإسلامية ثاني أقدم جامعة سعودية، وثالث أكبر جامعة سعودية من ناحية عدد الطلبة، ومن أوائل الجامعات السعودية التي شرعت باستقبال الطلاب الدوليين عبر برنامج المنح الدراسية، حيث بدأت الجامعة في استقبال الطلبة الدوليين منذ العام 1397هـ، وبلغ عدد المستفيدين حتى عام 1441هـ أكثر دن (59000) طالب دولي. ويستدعي هذه النمو في عدد الطلاب دراسته بشكل أكثر عمقًا؛ لمعرفة خصائصهم وسماتهم، والعوامل المؤثرة في اختيار وتحديد بلد الوجهة، وأسباب اختيارهم للجامعة، واتجاهاتهم في المستقبل، ودورهم في تتمية بلدانهم. وستُركّز الدراسة على طلاب المنح الوافدين، وتستهدف الطلاب الذين غادروا بلدهم الأصلي للدراسة في الخارج؛ ومن ثمّ سيُستبعد الطلاب الأجانب المقيمون في المملكة العربية السعودية من

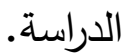

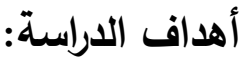
1- التطوّر التاريخي لأعداد طلاب المنح الدراسية الوافدين بجامعة الإمام محمد بن سعود الإسلامية. 2- التوزيع الجغرافي لطلاب المنح الدراسية الوافدين بجامعة الإمام محمد ابن سعود الإسلامية. 3- الخصائص الديموغرافية، الاجتماعية، والاقتصادية لطلاب المنح الدراسية الوافدين بجامعة الإمام محمد بن سعود الإسلامية. 4- التوجّهات المستقبلية لطلاب المنح الدراسية الوافدين بجامعة الإمام محمد بن سعود الإسلامية.
السعودية أكثر من مرة ونصف، بمعدل نمو سنوي يتجاوز 10\%، وتطلب هذه التغيّرات والزيادة في حركة الطلاب الدوليين بذل المزيد من الدراسات الجغرافية لتتبّع هذه الظاهرة ودراستها. مشكلة الدراسة: منذ نشأة المملكة العربية السعودية على يد المؤسس عبدالعزيز بن عبدالرحمن آل سعود - طيّب الله ثراهاهتمت المملكة بتنمية القوى البشرية ورفع كفاءتها عبر تطوير منظومة التعليم بجميع عناصرها، والاهتمام بمُخرجاتها، فثهدت المملكة العربية السعودية تطورًا وتوسّعًا في منظومة التعليم بجميع عناصرها واستثمرت المملكة العربية السعودية في السنوات الأخيرة بكثافة في الإصداحات التعليمية، والتوسّع في الجامعات والكليات؛ مما أسهر في زيادة الطلبة الدوليين الملتحقين بالتعليم العالي. وبعد أن كان عدهم (11465) طالب في عام 1400هـ ارتفع العدد إلى ما يقارب (73977) طالبًا في عام 1439هـ، ويمثّلون أكثر من (155) دولة. وقد استحدثت المملكة العربية السعودية برنامجًا للمنح الدراسية مخصّصًا للطلاب غير السعوديين للدراسة الجامعية في الجامعات السعودية، وتنقسم المنح إلى نوعين: منح داخلية للطلبة غير السعوديين المقيمين في المملكة إقامة نظامية، ومنح خارجية للطلبة الوافدين من خارج المملكة. ويُمثّل برنامج المنح أحد عوامل الجذب الرئيسة، بالإضافة إلى مكانة المملكة العربية السعودية الدينية لدى كافة المسلمين. 


$$
\text { علي معيض أحمد محمد القرني }
$$

وتعدُّ نظرية الطرد والجذب من أكثر النظريات التي ناقثت إشكالية الهجرة، وحلّلت الأسباب التي تدفع بالأفراد إلى الهجرة، ويمثّل ما توصّل إليه إيفرت لي لئل أفضل المحاولات لتفسير ظاهرة (Everett Lee)

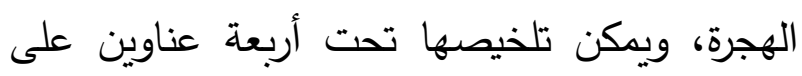
النحو التالي: العوامل المرتبطة بمنطقة الأصل،

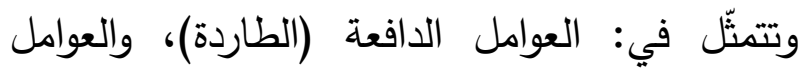
المرتبطة بمنطقة الوصول (الوجهة)، وتتمثّل في:

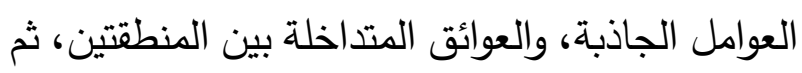
العوامل الثخصية، وتعمل هذه العوامل سويًّا في إحداث الهجرة ( 50-40e. 1966. pp. 49)،

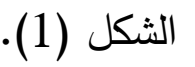

حدود الدراسة: الحدود الزمانية: اعتمدت الدراسة في بعدها الزمني على قسمين، وهما: القسم الأول: ما يتوفّر من بيانات إحصائية في المصادر الرسمية الرماني بالمملكة العربية السعودية: وزارة التعليم، وجامعة الإمام محمد بن سعود الإسلامية، والمصادر الأخرى كاليونسكو . والقسم الثاني: الاستبانة بوصفها مصدرًا رئيسًا لبيانات الدراسة، التي وُزّعت خلال الفصل الدراسي الأول من العام الجامعي 1441هـ

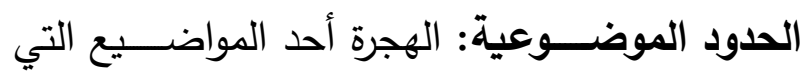
تدرس ضمن تخصّص جغرافية السكان؛ بوصف أنها

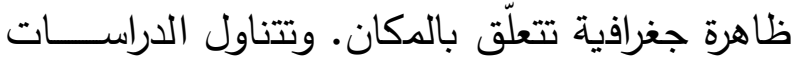
الجغرافية موضوعات مثل: اتجاهات الهجرة وأسبابها، ومن ضـــن الموضـــوعات: دراســة هجرة الطلاب الـدوليين من حيث عنـاصـــر الجذب وعواملـه، وخصـــــائصــــهم الــديموغرافيـة، والاجتمــاعيـة، والاقتصــادية، ودورهم في تتمية المناطق التي قِدموا منها، ومستقبلهم. الحدود المكانية: جامعة الإمام محمد بن سعود الإسلامية، المقر الرئيس بالرياض. الإطار النظري والدراسات السابقة: اهتم العلماء بمحاولة تقسير ظاهرة الهجرة، وكيفية اتخاذ قرار الهجرة؛ لكن العوامل المؤثرة في اتخاذ قرار الهجرة كثيرة ومعقّة؛ لأنها مرتبطة بعدد من العوامل

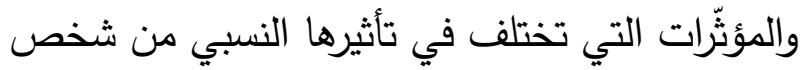
إلى آخر، وقد حاول العلماء تفسيرها وتعدّدت النظريات التي تتاولتها. 
شكل (1): نموذج الهجرة عوامل الافع والجذب.

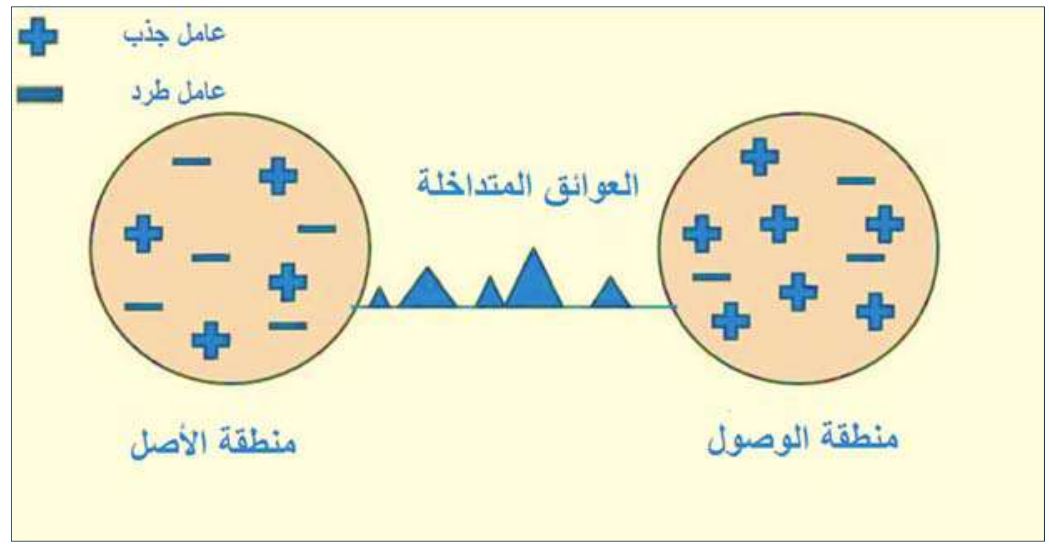

وأجرى السميح (2004م) دراسة عن الصعوبات التعليمية والإدارية لطلاب المنح الدراسية: دراسة ميدانية على طلاب المنح الدراسية بجامعة الإمام

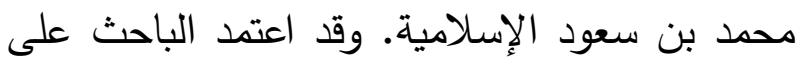

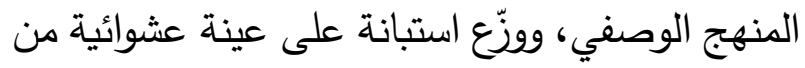

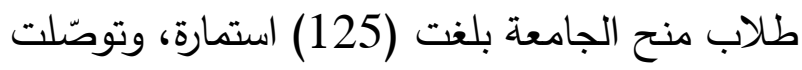

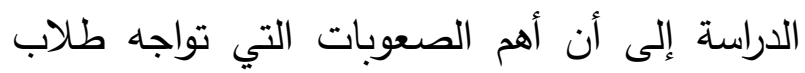

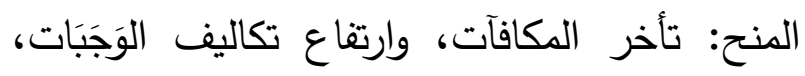
وكثرة عدد الطلاب الساكنين بشقة واحدة، وأظهرت

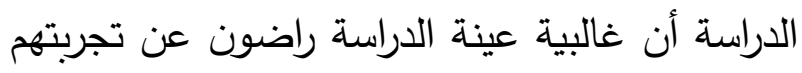

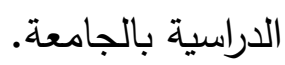
وأجرى أبا الخيل (2009م) دراسة عن استخدام الطلاب الأجانب المكتبات الجامعية: دراسة واقع مكتبة الأمير سلمان المركزية بجامعة الملك سعود،

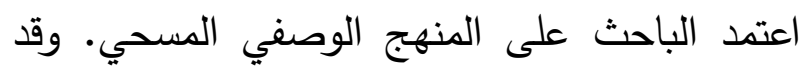
استخدم الباحث عينة عشوائية قدرها (190) طالبًا

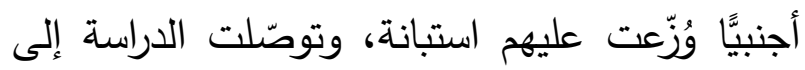

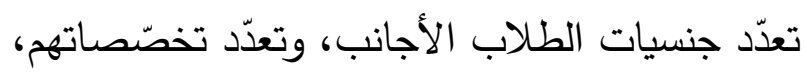

Lee, Everett .S. 1966: "A theory of migration”, Demography, Vol. 3, No. 1, $47-57$

ولأهمية هذه الظاهرة الســكانية، فقد تتاول العديد من الدراسات هجرة الطلاب الدوليين، ومنها: دراسة الصبيحي (1422هـ) عن تعليم أبناء المسلمين في عهد خادم الحرمين الثريفين: تجربة طلاب المنح الدراسية في جامعة الإمام محمد بن سعود الإسلامية (1402-1422هـ). حيث استعرض تاريخيًّا تطور عدد طلاب المنح الدراسية لكافة مراحل التعليم الجامعي داخل المملكة العربية السعودية، وفي فروع الجامعة الخارجية، كما سلّط الضوء على جهود خادم الحرمين الثريفين في تعليم أبناء المسلمين، وتوصّل إلى اتساع الرقعة الجغرافية التي غطّّها المنح الدراسية، واستمرارية برنامج المنح الدراسية؛ رغم الدماته تقلّبات الظروف الاقتصادية. 
البرنامج، وطرق اختيار الطلاب الدوليين، وأهداف

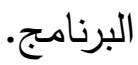

وقدّمت سوزان بيش Suzanne Beech (ليشنامج (2015م) دراسة عن هجرة الطلاب الدوليين: دور الثبكات الاجتماعية، وأجرت مقابلات مع ثمانية وثلاثين طالبًا دَوْلِيَّا في ثلاث جامعات بالمملكة المتحدة (جامعة أبردين، وجامعة نوتنغهام وكوينز ، وجامعة بلفاست)،

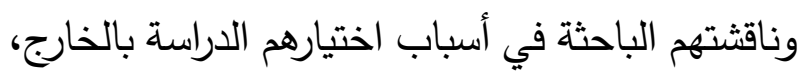
ودور الثبكات الاجتماعية في تقديم الدعم والمشورة لئاسي والتثجيع، ودورها في تأسيس ثقافة هجرة الطلاب

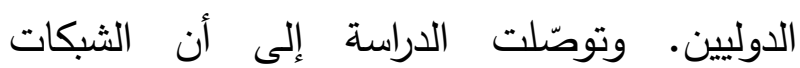
الاجتماعية عامل في تثكيل المناطق الجغرافية لحركة الطلاب الدوليين، كما أظهرت أن تجارب النياعل العائلة والأصدقاء الذي درسوا بالخارج، بالإضافة إلى الى الى إنى

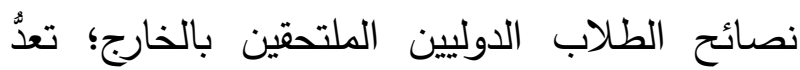
عاملًا مؤثرًا وحاسمًا في اختيار الدراسة بالخارج. وتتاول المحسن والسعوي (2015م) الاغتراب لدى لإن طلاب الهنح الوافدين بجامعة القصيم: مظاهره وسبل مواجهته، واعتمدا على المنهج الوصفي، واعتمدا على لـى لونى استبانة وُزّعت على (119) طالبًا من طلاب المنح الوافدين. وأظهرت الدراسة انخفاض درجة الاغتراب، كما أن من أهم المشكلات التي تواجه طلاب المنح: ضعف الخدمات اليُقدّمة إليهح عند قدومهم، وتأخر المكافأة الشهرية، وضعف دور الجامعة في ترتيب مقار السكن لهم، وإنهاء عملية تسجيلهم.
كما أن نسبة كبيرة من الطلاب الأجانب لم يسبق لهم زيارة المكتبة قبل مجيئهم إلى السعودية. هذا بالإضافة إلى تدني نسبة الطلاب الأجانب الملتحقين ببرامج الجولات التعريفية التي تقيمها عمادة شؤون المكتبات للطلاب المستجدين. وترى الأغلبية من الطلاب الأجانب أن الخدمات التي تُقدّمها مكتبة الأمير سلمان

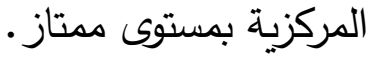
وتناول فايد (2014م) فاعلية الممارسة العامة في الخدمة الاجتماعية في التخفيف من الضغوط الحياتية لدى طلاب المنح الدراسية، واعتمد فيها على المنهج شبه التجريبي، وبلغ حجم العينة (30) طالبًا، وتوصّلت الدراسة إلى أن برامج التدخّل المهني لتوجيه طلاب المنح؛ ساعدت على التخفيف من حِّة الضغوط والمشكلات التي تواجههم. وقدّم سكوت باسفورد Scott Basford (2014م) دراسة عن هجرة الطلاب الدوليين من أجل التنمية: طريقة نظام الحصص للمؤسسة النرويجية. وقد ركّزت الدراسة على تدويل التعليم العالي والدولي بوصفه شكلًا من أشكال المساعدة التتموية، ودراسة النظام النرويجي بوصفه شكلا من أشكال المساعدات الإنمائية، وأُجريت مقابلة مع (31) من الطلبة المستفيدين من النظام؛ لمناقثة آليات عمل البرنامج، معله وأسباب الهجرة، وآليات دمج الطلاب الدوليين اجتماعيَّا وأكاديميَّا، كما أُجريت مقابلات مع الإدارة المسؤولة عن برنامج الحصص؛ لمناقثة آليات عمل 
طلاب الهنح الخارجية: هم الطلاب غير السعوديين، الذين هاجروا من بلادهم هجرة مؤقتة؛ لمواصلة تعليمهر الجامعي وإكماله في المملكة العربية السعودية، ويعودون إلى بلادهم بعد تحقيق الهدف.

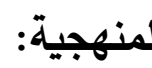

اعتمدت الدراســـة على المنهج الوصــفي التحليلي؛ للاستفادة منه في تحليل المعلومات والبيانات، مع ما يتبع ذلك من خطوات إجرائية يسـتلزمها هذا المنهج،

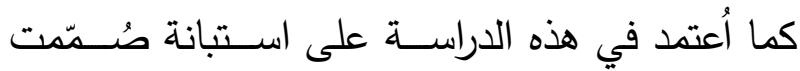
للحصول على المعلومات المطلوبة. مجتمع الاراسة:

يشمل جميع طلاب المنح الوافدين في المقر الرئيس لجامعة الإمام محمد بن ســعود الإنســلامية بمدينة

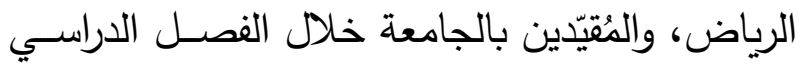

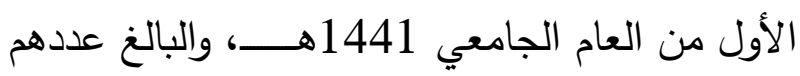

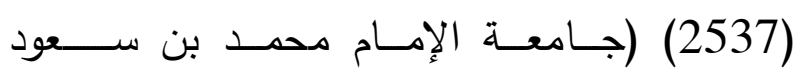

$$
\text { الإسلامية،2019م). }
$$

عينة الدراسة:

حُدّد حجم العينة الكلي باســـتخدام معادلة ســـتيفن

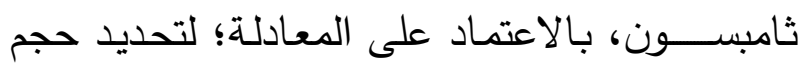
العينـة بدقة (95\%)، ومســتـوى الدلالـة (0.05)

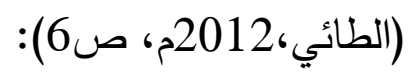
$n=\frac{N \times p(1-p)}{\left.\left.\llbracket N-1 \times\left(d^{2} \div z^{2}\right)\right]+p(1-p)\right]}$
كما درس القرني (2018م) بعض مشكلات طلاب المنح الدراسية بجامعة تبوك، والآليات الإجرائية لمعالجتها: دراسة ميدانية. وقد استخدم الباحث استبانة

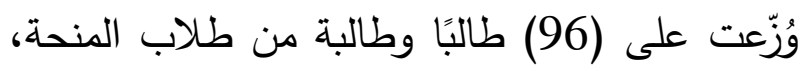
وتوصّل إلى أن أهم المشكلات التي تواجههم:

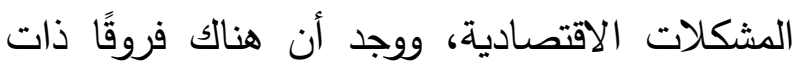
دلالة إحصائية للطلاب عن الطالبات بالمشكلات الكلية، كما وجد أن الفروق بالمشكلات كانت لصالح التخصّصات العلمية، ولا توجد فروق ذات دلالة إحصائية بين طلاب قارتي آسيا وأفريقيا.

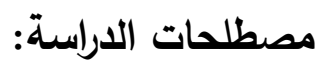
الطلاب الدوليون: هم الطلاب الذين عبروا حدودًا وطنية أو إقليمية لغرض التعليم، وهم الآن مسجّلون خارج بلدهم الأصلي (اليونسكو،2015).

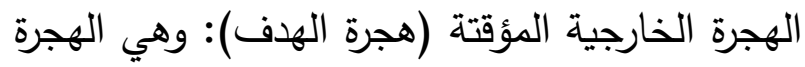
التي يقوم بها بعضهم بشكل مؤقت؛ لهدف ما وهي

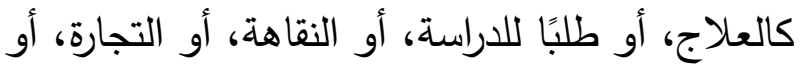

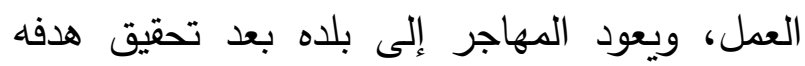
(العيسوي،2005م، ص صن 288). المنح الدراسية: مقعد يحصل عليه الطالب (الذكر أو الأنثى) من غير السعوديين، للدراسة في مؤسسات

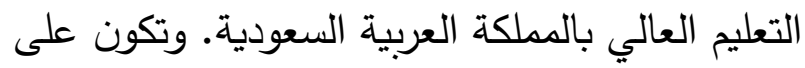

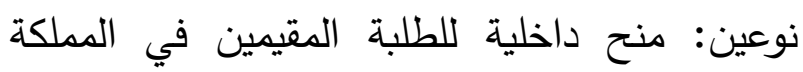
العربية السعودية، ومنح خارجية للطلبة من خارج 
تستقطب الطلاب الدوليين في الجامعات السعودية، ففي هذا التاريخ أنشئت الجامعة الإسلامية، التي خُصَص \%85\% من مقاعدها لطلاب المنح. وصدر في عام 1400هـ قواعد المنح الدراسية لجامعات المملكة، وهدفت هذه القواعد إلى تتظيم قبول واستقدام الطلاب غير السعوديين الدارسين بمنح دراسية، وأسلوب رعايتهم، ومميزات المنحة الدراسية، كما

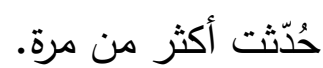
وبالنظر إلى أقدم الإحصاءات عن عدد طلاب المنح بالجامعات السعودية؛ يتبيّن أن وزارة التعليم (وزارة التعليم العالي في ذلك الوقت) بدأت برصد طلاب المنح منذ العام الجامعي 1397/ 1398هـ، وبلغ عدد طلبة المنح المستجدين سنويًا منذ العام الجامعي 1398/1397هـ، وحتى العام الجامعي 14381439هـ (635694) طالبًا وطالبة، بمعدّل زيادة

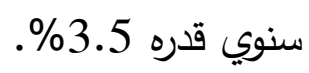
وبالنظر إلى الشكل (2)؛ يتضح أن معدّلات التحاق طلاب المنح خلال الفترة من 1397هـ، وحتى العام 1410هـ؛ شهد زيادة في عدد الطلاب، وقد يعود ذلك إلى أن الفترة من عام 1390هـ، وحتى العام 1410هـ أنثىء فيها (4) جامعات جديدة؛ مما أدّى إلى زيادة فرصة قبول عدد طلاب منح أكبر ، وبمعدل نمو سنوي 3.19 خلال هذه الفترة. وقد شهد العام الجامعي 1400 - 1401هـ أعلى عدد للمنح الدراسية المُقدّمة؛ حيث بلغت (19808) منحة دراسية.
وبعد تطبيق المعادلة؛ حُصــلـل على عدد أفراد العينة التي تبلغ (324) طالبًا، وسُــــــبت عينـة الدراســـــة بطريقة العينة العشوائية البسيطة. أداة الاراسةِ (الاستبانةُ): اعتمدَ الباحثُ على الاستبانةٍِ؛ بوصفها وسيلةً لجمعِ المعلوماتِ اللازمةِ التي تحقّقُ أهدافَ الدراسةِ. وقذ حُكمّتت منْ قبلِ عددٍ منْ المتخصصينَ، وأفادوا بمناسبةٍ فقراتها وملاعمتها لموضوعِ الدراسةِ؛ ومنْ ثَ عمل اختبارِ لها عنْ طريقِ إجراءِ دراسةٍ ميدانيةٍ مبدئيةٍ استطلاعيةٍة، ووزعتُ الاستبانةُ خلالَ فترةٍ منْ 1441/2هـ، إلى 1441/4 148ه، وأستعين ببرنامجٍ (SPSS)؛ لإدخالِ البياناتِ وترميزها إلى الحاسبِ الآلي؛ بهدفِ إجراءِ التحليلاتِ الكميةِ، كالتكراراتِ

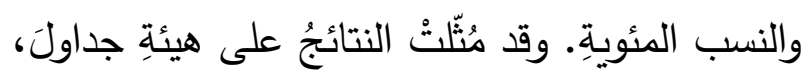
ورسوماتُ بيانيةٌ، وخرائطُ، واستخدمتُ في تحليلِ النتائج وعرضها. النتائج والمناقشة: التطوّر العددي والجغرافي: يعدّ التعليم الجامعي بمفهومه الحديث حديثًا نسبيًّا في المملكة العربية السعودية، وليس من اليسير على الباحث أن يُحدّد تاريخًا معينًا لبداية التحاق الطلاب مئه الدوليين بجامعاتها؛ ويمكن القول: إن البداية الأولى كانت منذ إنشاء أول جامعة سعودية بتاريخ 1377هـ، ومنذ هذا التاريخ التحق عدد من الطلاب الدوليين بالجامعات بشكل فردي وغير منظّم، ويمثّل العام 1381هـ البداية الفعلية لبرامج المنح الدراسية، التي 
التعليمية، والتوسّع في الجامعات والكليات؛ فقد أنفقت المملكة خلال العقد الماضي نحو (2.231) تريليون

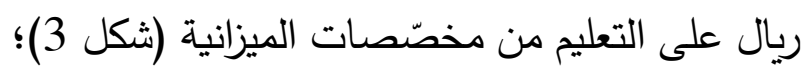
وانعكس ذلك في زيادة عدد الطلاب الدوليين المقيّدين

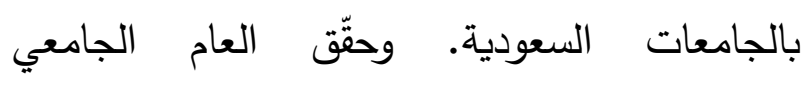
1437/1436هـ أعلى عدد من الطلبة الدوليين المقيّدين، بعدد (79854) طالبًا دوليَّا. وفي عام

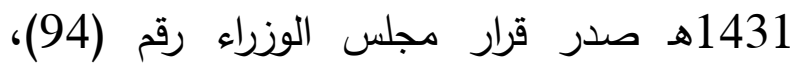
مُنضمّنًا ضوابط قبول طلاب المنح الدراسية لغير السعوديين في مؤسسات التعليم العالي بالمملكة العربية السعودية ورعايتهم، وفي هذه الفترة زادت عدد

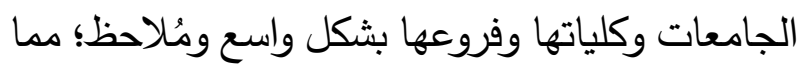
أسهم في هذه الزيادة، وبلغ معدل النمو السنوي 8.92 خلال هذه الفترة. وشهد العام الجامعي 1438-1439هـ أعلى عدد للمنح الخارجية الدراسية الكُقدّمة، حيث بلغت (37969) منحة دراسية.
أما خلال الفترة 1410 وحتى العام14241425هـ فقد شهد معدل قبول الطلبة انخفاضًا، وربما يعود ذلك إلى أن عدد الجامعات لم يطرأ عليه زيادة تُكر ، وأن الجامعات التي أُنشئت في هذه الفترة؛ هي لفي

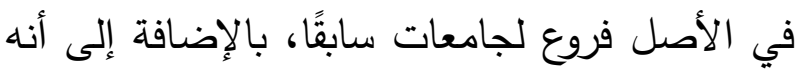

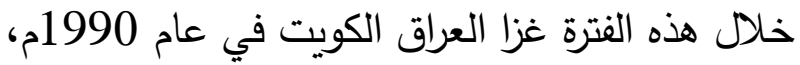
وعانت الدول الخليجية عامة، والمملكة العربية

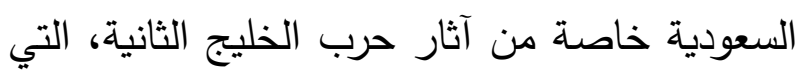
تَدمّز فيها الاقتصاد والبنية التحتية للكويت، ودفعت الدول الخليجية فاتورة الحرب، مع انخفاض أسعار النفط؛ مما أسهم في انخفاض عدد طلاب المنح المقبولين، وبلغ معدل التغير -1.25\% سنويًّا. وشهدت الفترة من العام الجامعي 1424-1425هـ، إلى العام الجامعي 1438-1439هـ أعلى زيادة في عدد طلاب المنح بالجامعات السعودية منذ نشأتها، وجاءت هذه الزيادة نتيجة لاستثمار المملكة العربية

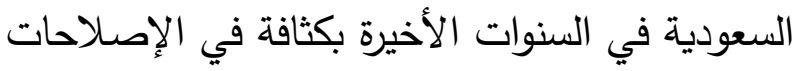
شكل (2): القبول السنوي لطلاب المنح بالجامعات السعودية.

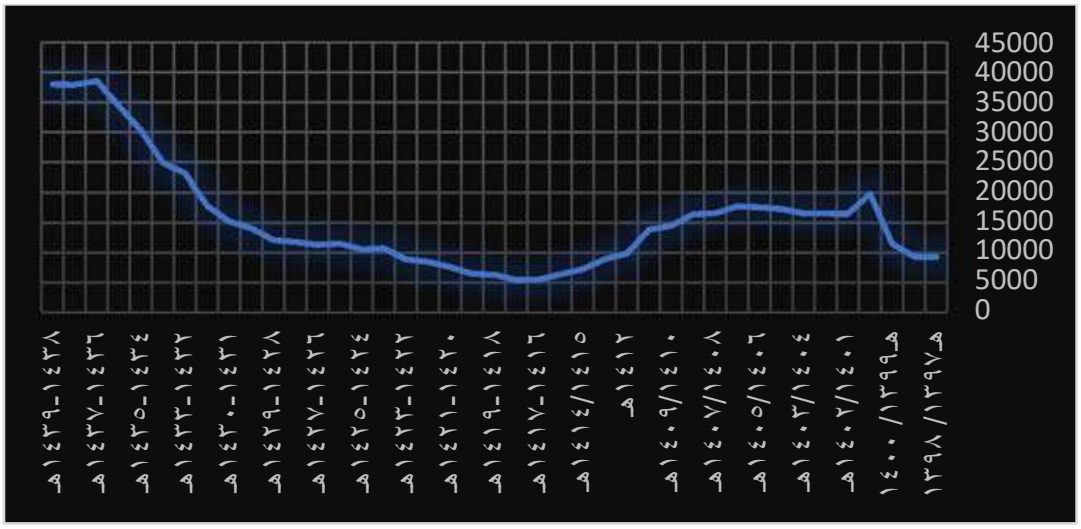

المصدر : وزارة التعليم. (2018). قاعدة بيانات إحصائيات التعليم الجامعي. تاريخ دخول الموقع: 1440/10/8هـ. https://departments.moe.gov.sa/PlanningDevelopment/RelatedDepartments/Educationstatisticscente r/EducationDetailedReports/Pages/default.aspx 


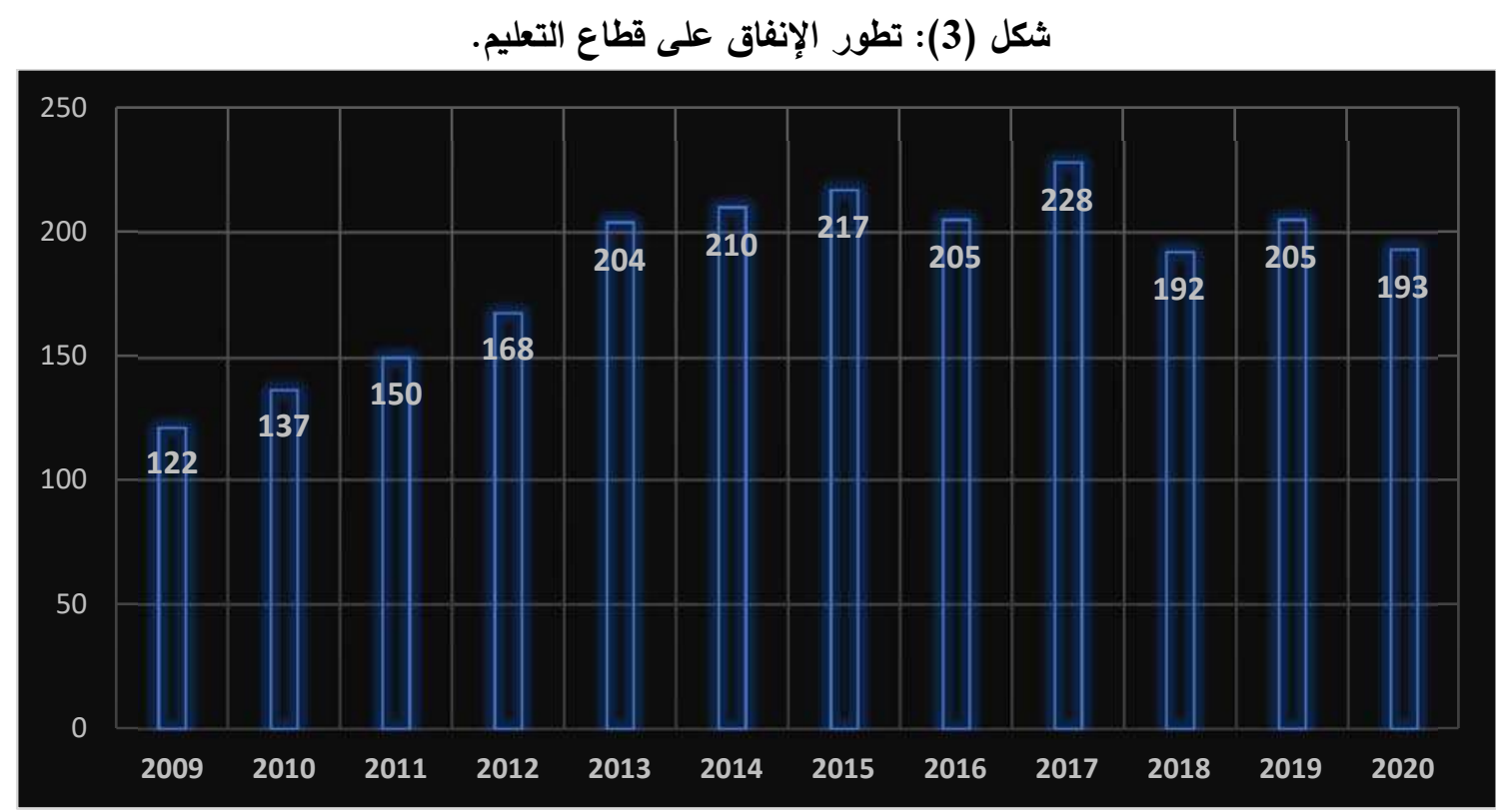

المصدر : وزارة المالية. (2020م). المكتبة الرقية (بيانات الميزانية). تاريخ دخول الموقع: 1441/12/28هـ. https://www.mof.gov.sa/docslibrary/Budget/Pages/default.aspx

- - تبليغ رســالة الإســـلام إلى العالم، وتعليم اللغة العربية، ونشر ثقافة الوسطية والاعتدال. - - إعداد علماء متخصّصين فاعلين في مجتمعاتهم بجميع التخصّصـات. - - استقطاب الطلبة المتميّزين علميَّا لتحقيق التنوّع، وإثراء البحث العلمي. - - إقامة الروابط العلمية والثقافية مع المؤسـســـات التعليمية والهيئات والمؤسـسـات والإسـلامية والعلمية في العالم، وتوثيقها لخدمة الإنسانية. - تعزيز التضامن بين المملكة ودول طلاب المنح.

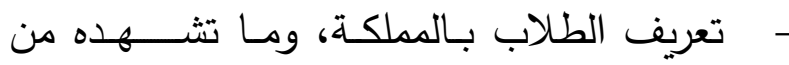
نهضــة: علمية، واقتصـادية، وسـياسـية، واجتماعية، وصحية. وقـد بــدأ برنــامج المنح الـدراســـــــة في العـام

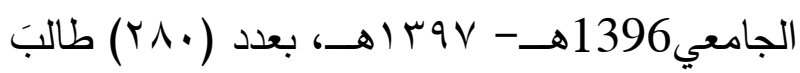

طلاب المنح بجامعة الإمام محمد بن سعود

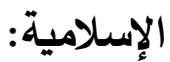
شـــدت المملكة العربية الســعودية تطورًا اقتصـــاديَّا واجتماعيَّا وعلميَّا في كافة المجالات، وكانت النواة الأولى للجـامعـة المعهـد العلمي في الريـاض عـام 1370هـــــ، بتوجيه من الإمام المؤسـس الملك عبد العزيز بن عبدالرحمن الفيصل آل سعود - طيّب الله ثراه - ومن ثمّ افتتاح كلية الثــــريعة بالرياض عام

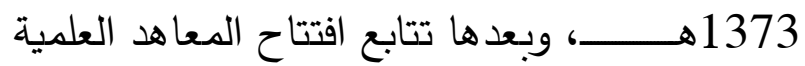
والكليات. وقد بادرت المملكة العربية السـعودية منذ وقت مبكر إلى تقديم المنح الدراســـية لمختلف جامعاتها، وتعدّ جامعة الإمام محمد بن ســعود الإســلامية من أوائل الجامعات التي ســــاهمت في تحقيق أهداف برنامج المنح الدراسية لغير السعوديين، والمُتمثّل في الآتي: 
نمو ســـنوي قدره 12.63\%؛ لكن خلال الفترة من منحـة في المرحلتين الجـامعيـة والدراســــات العليا

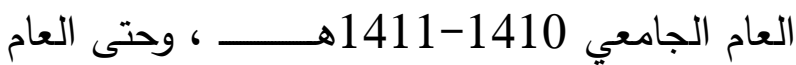
(الصـبيحي،1423هـــ، ص 35). وتطوّر برنامج

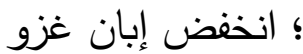
الجامعي 1430-1429هـ

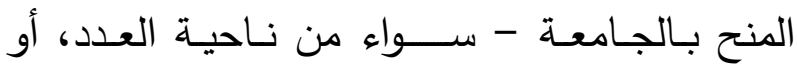
العراق للكويت، وما تلا ذلك سـنوات واجهت المملكة

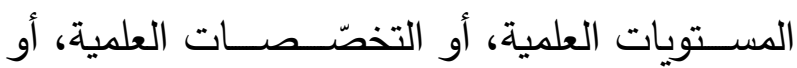

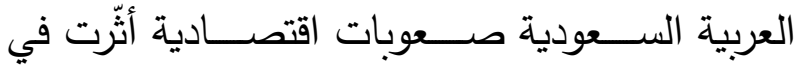
التغطية الجغرافية للبرنامج-ولم يقتصـر على طلاب انخفاض أعداد الطلاب المقبولين ببرامج المنح.

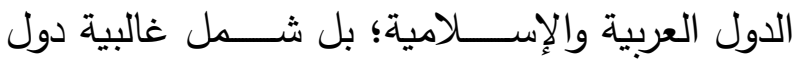

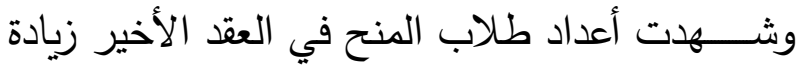

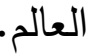
ملحوظـة، وقد يعود ذلك إلى زيـادة أعداد الطلاب

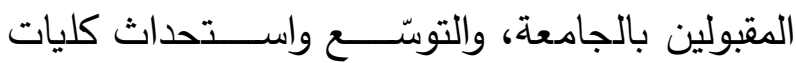
وتخصّصات وبرامج متنوّعة؛ ساهمت في زيادة جذب ونب طلاب المنح. وقد شـــــد العام الجامعي 1438-

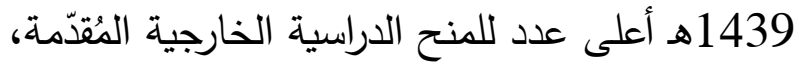
حيث بلغت (3063) منحة دراســية. وبشــكل عام،

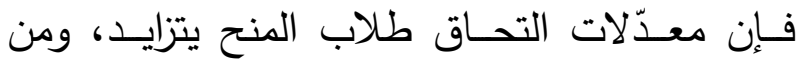
المرشّح أن ترتفع نسبتهم في المستقبل. شكل رقم (4): طلاب المنح الوافدين بجامعة الإمام محمد بن سعود الإسلامية.

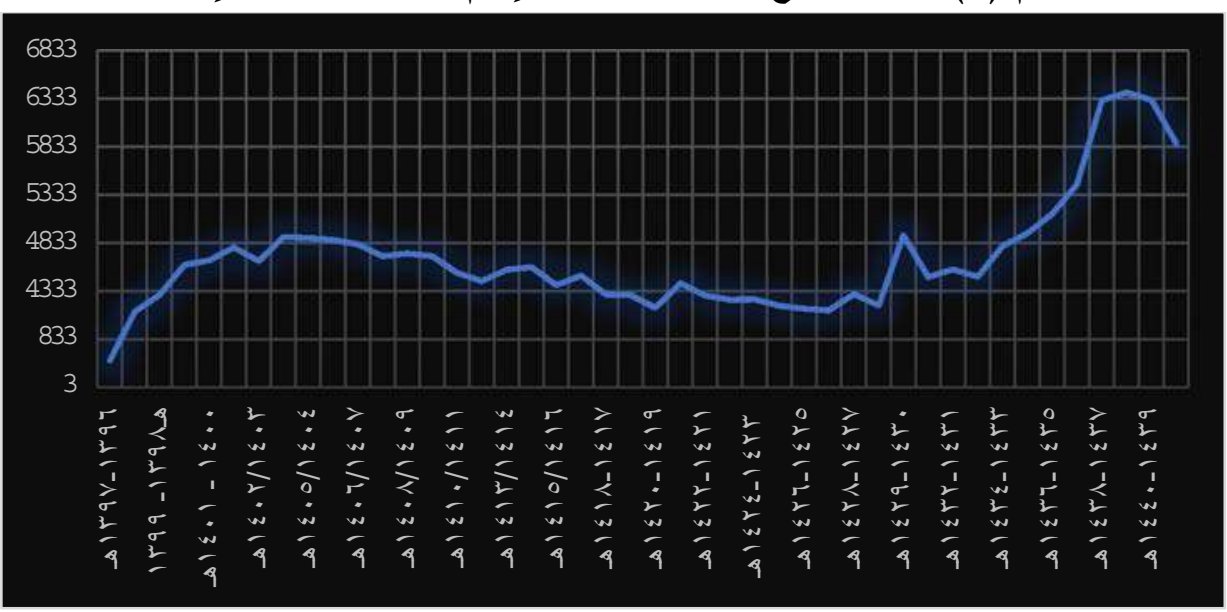

المصدر : وزارة التعليم. (2018م). قاعدة بيانات إحصائيات التعليم الجامعي. تاريخ دخول الموقع: 1440/10/8هـ. https://departments.moe.gov.sa/PlanningDevelopment/RelatedDepartments/Educationstatisticscente $\underline{\mathrm{r} / \text { EducationDetailedReports/Pages/default.aspx }}$ 
اليمنية والسورية أعلى نسبة، وهذه الزيادة في نسبتهم التوزيع الجغرافي: متوقّعة؛ حيث استقبلت المملكة الملايين من السورينين نظرًا لقِدم برنـامج المنح، ولتعدّد المعـاهد الخـارجيـة واليمنيين منذ اندلاع الحرب الأهلية ببلادهم.

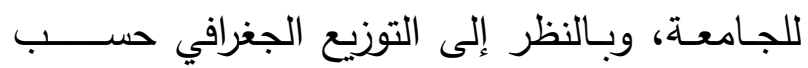
وخصّصت جامعة الإمام محمد بن سعود الإسلامية القارات؛ يتضـــح أن غالبية طلاب المنح الوافدين من ثلث مقاعد طلاب المنح لـ (19) دولة عربية. قارة آسـيا وأفريقيا بنسـبة 94\%، وقد أتت قارة آسـيا كما تبيّن أن غالبية طلاب المنح في المرحلة الجامعية أولًا بوصــفها أعلى قارة قَدِم منها طلاب المنح، تليها بنسبة 74\%، يلي ذلك طلاب الدراسات العليا بنسبة قارة أفريقيا، ثم بقية القارات بنسبة 6\%، الشكل (5). 17\%، وأخيرًا طلاب الدبلوم بنسبة 9\%، كما يتبيّن ويتوزع طلاب المنح حسب جنسياتهم إلى (88) دولة، وتفاوتت أعدادهم بحسب الجنسية، فجاءت الجنسية من الشكل (6). شكل (5): التوزيع الجغرافي لطلاب المنح الوافدين حسب القارات.

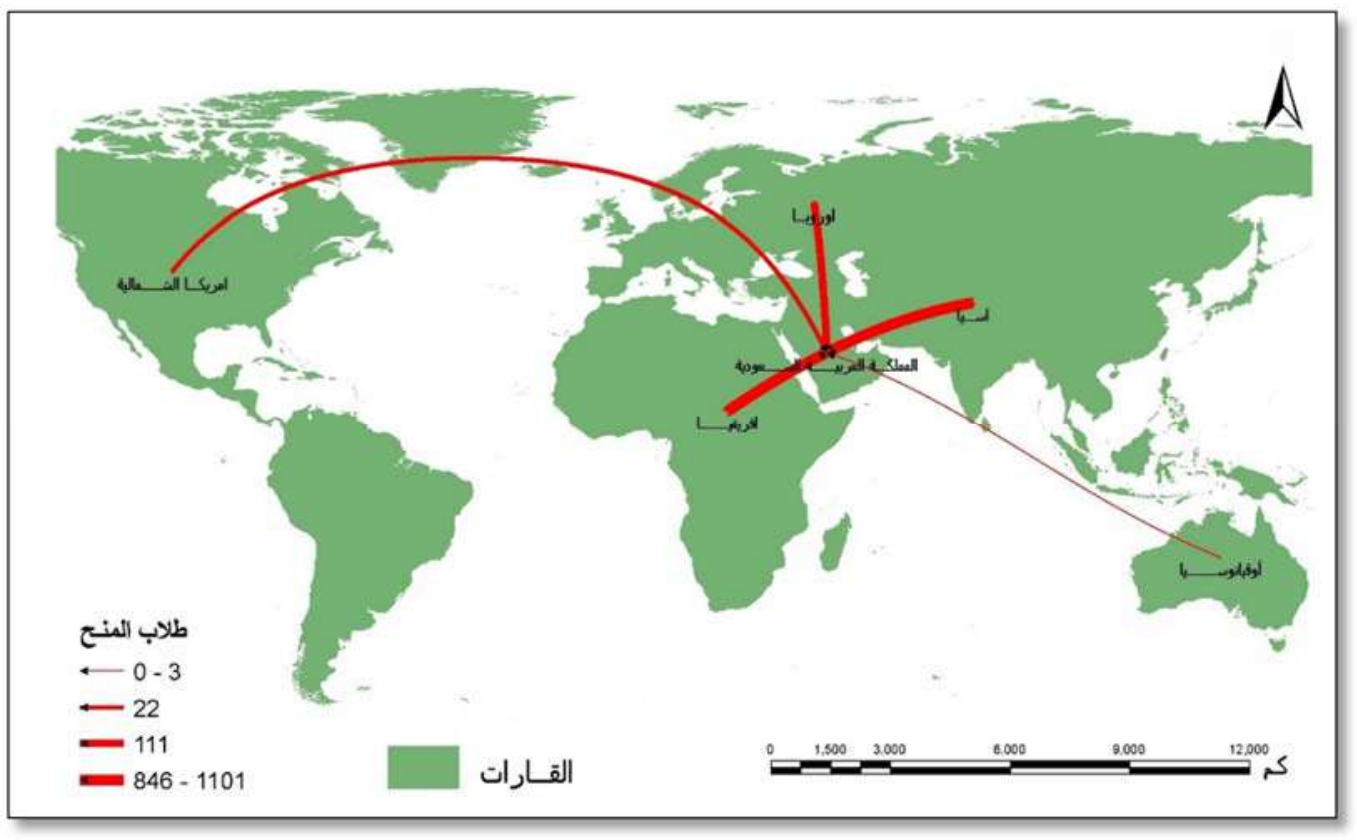

المصدر : جامعة الإمام محمد بن سعود الإسلامية. (2019م). قاعدة بيانات طلاب المنح الدراسية للفصل الدراسي الأول للعام الجامعي 1441هـ.عمادة شؤون الطلاب. 
شكل (6): عدد طلاب المنح الوافدين حسب المرحلة الدراسية.

عدد طلاب المنت حسب المرحلة الدراسية

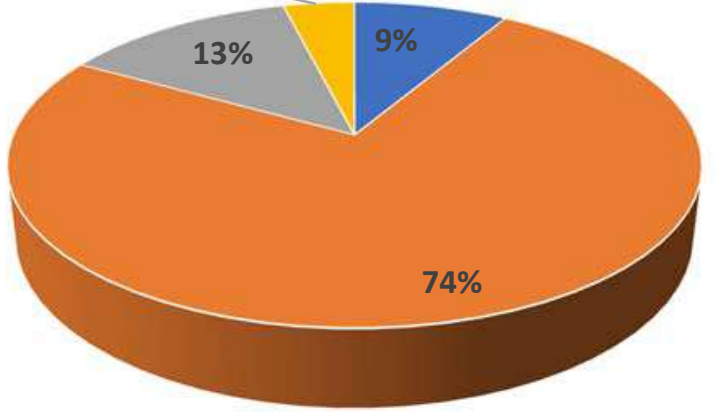

| دكتوراه - ماجستير - المرحلة الجامعية - دبلوم

المصدر : جامعة الإمام محمد بن سعود الإسلامية. (2019م). قاعدة بيانات طلاب المنح الدراسية للفصل الدراسي الأول للعام

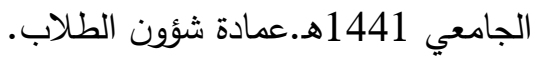

العينة بنسبة 74.7\%، ويتناسب هذا الدخل مع نظام الخصائص الايموغرافية: مكافآت طلاب المنح، أما الربع المتبقي من أفراد بلغ متوسط عمر أفراد عينة الدراسة (26.5)، ويعود العينة، فبلغ متوسط دخلهم من (1000-1500) ذلك إلى أن ثلاثة أرباع الطلاب في مرحلة البكالوريوس، كما أن شروط وزارة التعليم لقبول طلاب ريال. وفيما يتعلّق بمقدار ما يتم إنفاقه في المملكة العربية المنح منها العمر، حيث لا يقلّ عمر الطالب عن السعودية من إجمالي دخلهم الثهري؛ فاتضح أن قرابة (17) عامًا لطلبة البكالوريوس ومعهد تعليم اللغة نصف أفراد عينة الدراسة (47.5\%)، ينفقون ما بين دخلهم كاملًا أو ثلاثة أرباع دخلهم؛ بينما بلغت نسبة العربية أو ما يماثله، ولا يزيد عن (25) عامًا، ولدرجة الماجستير لا يقلّ عن (30) عامًا، و (35) عامًا

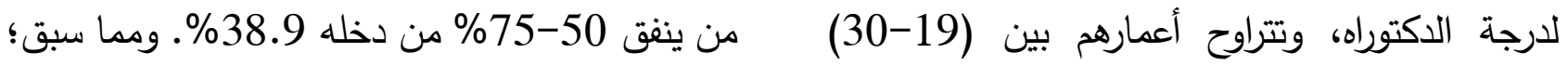
عامًا، بنسبة 90\% من عينة الدراسة، وهو السنّ يتبيّن أن غالبية عينة الدراسة تتفق أكثر من نصف دخلها بنسبة قدرها 86.4\%. المتوقّع لطلاب التعليم الجامعي. الخصائص الاقتصادية:

يوضّح الجدول (1) توزيع أفراد العينة حسب متوسط الدخل الشهري، ونجد أن طلاب المنح البالغ متوسطات دخولهم من (500-1000) ريال أعلى الفئات؛ حيث تستحوذ على قرابة ثلاثة أرباع أفراد 
جدول (1): متوسط الدخل الثهري.

\begin{tabular}{|c|c|c|}
\hline النسبة \% & 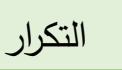 & 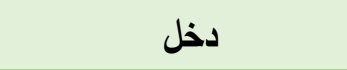 \\
\hline 74.7 & 242 & من 500_1000ريال \\
\hline 25.3 & 82 & من 1000_1500ريال \\
\hline 100 & 324 & الإجمالي \\
\hline \multicolumn{3}{|c|}{ جدول (2): متوسط الإنفاق الشهري. } \\
\hline النسبة \% & 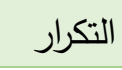 & إنفاقك \\
\hline 47.5 & 154 & من الدخل 75 -100\% \\
\hline 38.9 & 126 & 75-75\% من الاخل \\
\hline 11.1 & 36 & 25-50\% من الاخل \\
\hline 2.5 & 8 & أقل من 25\% من الدخل \\
\hline 100 & 324 & الإجمالي \\
\hline
\end{tabular}

المتوسط العالمي، ويؤكد ذلك أن أكثر من نصف

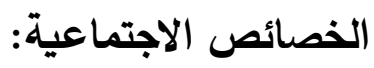
أظهرت بيانات الدراسة أن نصف عينة الدراسة المتزوجين تزوّجوا قبل قدومهم إلى الدراسة بالمملكة.

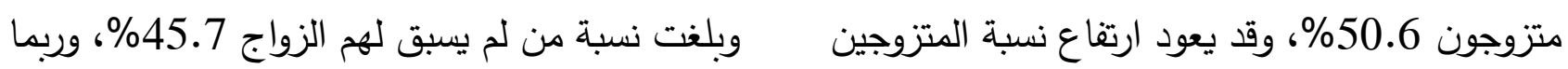

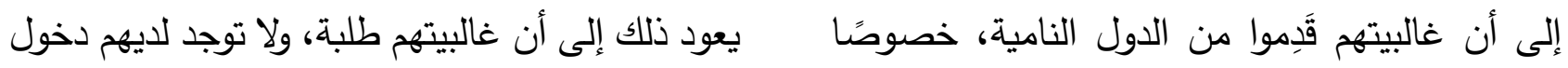

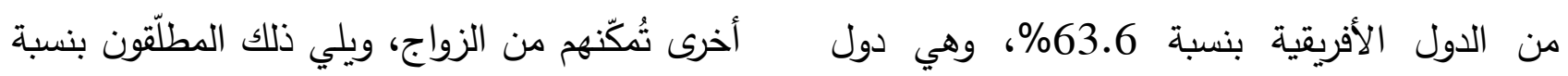

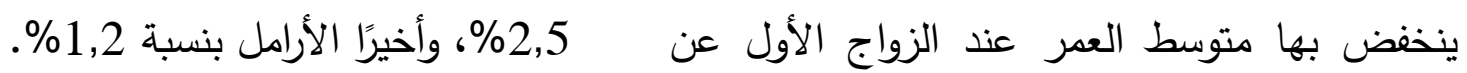
جدول (3): الحالة الاجتماعي.

\begin{tabular}{|c|c|c|}
\hline النسبة\% & التكرار & الحالة الاجتماعية \\
\hline 45.7 & 148 & لم يسبق لك الزواج \\
\hline 50.6 & 164 & متزوج \\
\hline 1.2 & 4 & أرمل \\
\hline 2.5 & 8 & مطلق \\
\hline 100 & 324 & الإجمالي \\
\hline
\end{tabular}

وفيما يتعلّق بإقامة العائلة في المملكة؛ يتضح أن 92\% لا تقيم عائلاتهم معهم، ويعود ذلك إلى عدم القدرة المادية؛ لضعف مدخولات غالبية عينة الدراسة. 
تؤكّد أن الطلاب الأجانب غالًَا مسجّلون في برامج

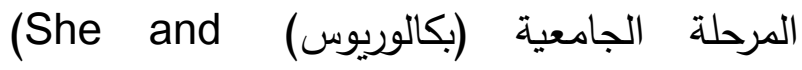
Wotherspoon. 2013.p:8) الدبلوم (معهد اللغة) بنسبة 12.3\%، ومن برامج الماجستير بنسبة 9.3\%، وأخيرًا برامج الدكتوراه بنسبة 1.2\%، كما يتضح من الجدول (4).
كليات طلاب المنح ومستوياتهم الدراسية: بالنسبة لتوزيع أفراد عينة الدراسة حسب المرحلة الدراسية؛ فغالبية عينة الدراسة ملتحقون ببرامج البكالوريوس بنسبة 77.2\%، ويتفق ذلك مع العديد

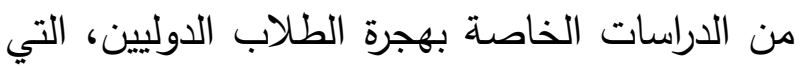

\begin{tabular}{|c|c|}
\hline \% النكرار & 40 \\
\hline 12.3 & 250 \\
\hline 77.2 & 30 \\
\hline 9.3 & 4 \\
\hline 1.2 & $\mathbf{3 2 4}$ \\
\hline 100 & \\
\hline
\end{tabular}

المؤهل

معهة تعليم اللغة (دبلوم) بكالوريوس ماجستير دكتوراه الإجمالي

\section{جدول (4): المراحل الاراسية.}

الجامعة، فهي تساعد على تهيئة علماء متخصّصين في العلوم الإسلامية والعربية، وفقهاء في الدين. في

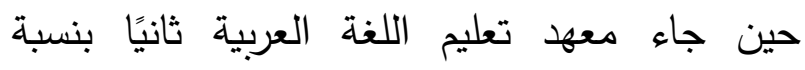

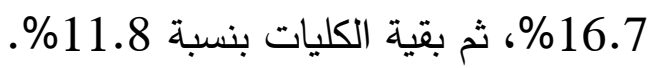

ومن خلال بيانات الجدول (5)؛ يتبيّن أن غالبية أفراد العينة يتركّون في الكليات الثرعية واللغة العربية، ويعود ذلك إلى أن جامعة الإمام محمد بن سعود جامعة إسلامية، ويوجد بها ثلاث كليات شرعية وكلية للغة العربية. وتُعدّ هذه النقاط أحد أهم نقاط قوة جذب لتب جدول (5): توزيع عينة الدراسة حسب الكليات والمعاهد.

\begin{tabular}{|c|c|c|}
\hline النسبة\% & التكرار & الكلية \\
\hline 1.2 & 4 & المعهة العالي للقضاء \\
\hline 3.7 & 12 & كلية العلوم الاجتماعية \\
\hline 16.7 & 54 & معهـ تعليم اللغة العربية \\
\hline 0.6 & 2 & كلية الاقتصاد والعلوم الإدارية \\
\hline 1.9 & 6 & كلية علوم الحاسب والمعلومات \\
\hline 8 & 26 & كلية اللغة العربية \\
\hline
\end{tabular}




\begin{tabular}{|c|c|c|}
\hline 2.5 & 8 & كلية \\
\hline 3.7 & 12 & كلية الإعلام والاتصات والترجمة \\
\hline 37.7 & 122 & كلية الشريعة أصول الدين \\
\hline 24.1 & 78 & الإجمالي \\
\hline 100 & 324 & \\
\hline
\end{tabular}

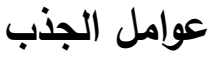

المنح الاراسية بوصفها عامل جذب:

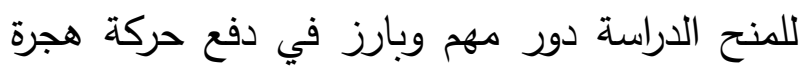
الطلاب، وقد أسهمت في زيادة الهجرة، وغالبًا ما يتأثر الطلاب بتكلفة المعيشة، والرسوم الدراسية، وجادبية الوجهة الدراسية. وبالنظر إلى المنح الدراسية الخارجية

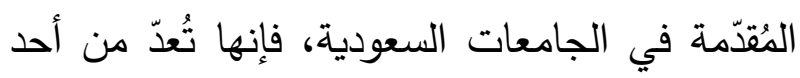
أهم برامج الاستقطاب؛ لتعدَد مزاياه ومنافعه، التي كإني جرى تطويرها أكثر من مرة؛ حتى صدر النظام الأساسي بقرار من مجلس الوزراء في عام 1431هـهـ ينظّم ضوابط القبول لطلاب المنح الدراسية ورعايتهم. وبسؤال عينة الدراسة عن جهة تمويل الدراسة؛ فاتضح

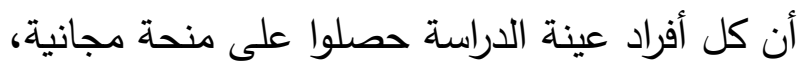
يحصل الطالب فيها على كامل الززايا التي تثمل:

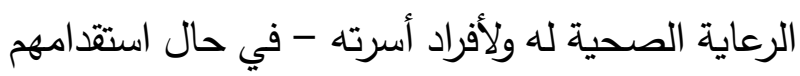

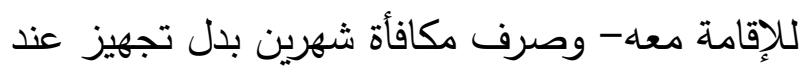

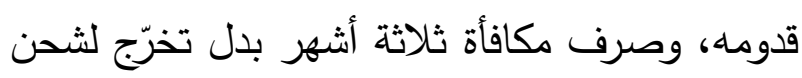

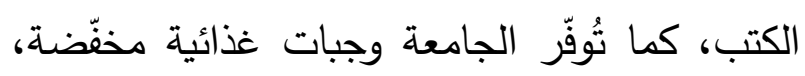
وتوفّر السكن والرعاية العلمية والاجتماعية والثقافية والتدريبية المناسبة، وصرف التذاكر حسب النظام... كما أن غالبية عينة الدراسة حصلوا على فرصة

\section{مدة الإقامة في المملكة العربية السعودية:}

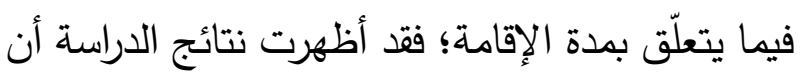

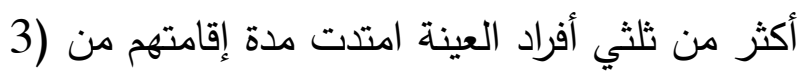

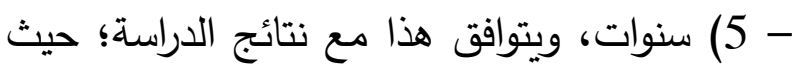
جاء ثلاثة أرباع عينة الدراسة في مرحلة البكالوريوس، وتلا ذلك أفراد العينة ممن تمتد مدة إقامتهم ما بين

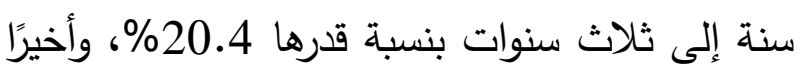
من تمتد مدة إقامتهم في المملكة ما بين (5) إلى أكثر

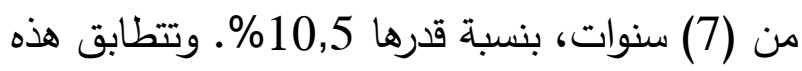
النسبة مع نسبة طلاب مرحلتي الماجستير والدكتوراه لأفراد العينة، التي قد تتطلّب مدة إقامتهم سنوات أكثر من سنوات المرحلة الجامعية. كما أن متوسط معدلات التات التهات طلاب المنح أكثر من (4 من 5)، وبلغت نسبة من حصل على إنذار أكاديمي 8\% من عينة الدراسة؛ ويفسّر هذا انخفاض مدة بقائهم في المملكة العربية السعودية. وهذا ما لاحظه الباحث في أثناء الدراسة

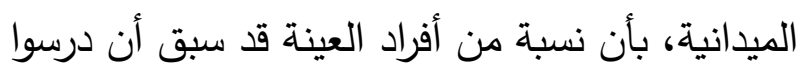
وتعلَّوا اللغة العربية وبعض العلوم الثران الثرعية قبل قدومهم إلى المملكة العربية السعودية. 
لإكمال تعليمهم في بلدانهم الأصلية بنسبة قدرها لجاذبيتها من ناحية الخدمات المُقدّمة ببرنامج المنح

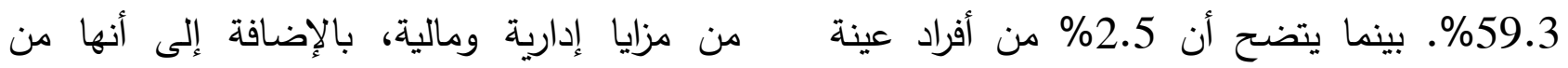
الدراسة حصلوا على منحة تعليمية لإكمال تعليمهم ببلد الجامعات المميّزة بالجوانب الثرعية واللغة العربية،

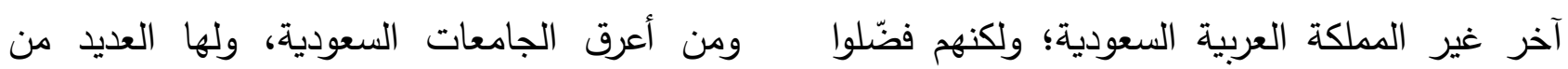

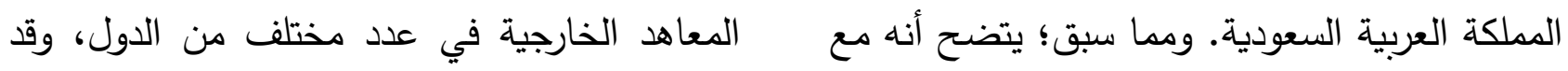
وجود فرص تعليمية ببلدهم وبلدان أخرى؛ لكنهم فضّلوا يكون ذلك من أهم أسباب تفضيل الدراسة بها. الالتحاق بجامعة الإمام محمد بن سعود الإسلامية؛

جدول (6): الفرص لإكمال الاراسة بيلد طالب المنحة.

\begin{tabular}{|c|c|c|}
\hline النسبة \% & التكرار & فرصة \\
\hline 59.3 & 192 & نعم \\
\hline 40.7 & 132 & ע \\
\hline 100 & 324 & الإجمالي \\
\hline
\end{tabular}

جدول (7): الحصول على منحة تعليمية ببلد آخر .

\begin{tabular}{|c|c|c|}
\hline النسبة \% & التكرار & تعليمية \\
\hline 2.5 & 8 & نعم \\
\hline 97.5 & 316 & ע \\
\hline 100 & 324 & الإجمالي \\
\hline
\end{tabular}

ويلي ذلك من سهّل لهم مؤسسة بنسبة 19.1\%، ثم

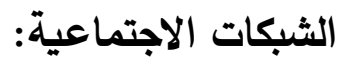
بصفة شخصية بنسبة 14.8\% يُشير العديد من الدراسات إلى أهمية الثبكات وبسؤال أفراد العينة عن وجود أحد أفراد أسرته يدرس بنسيه

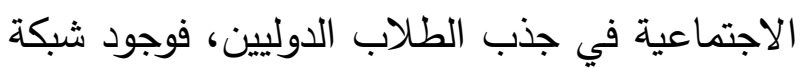

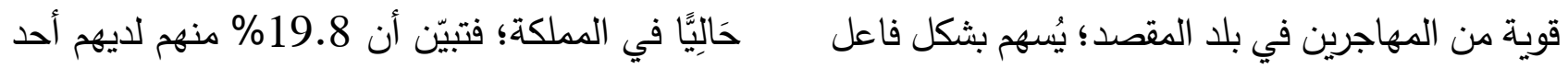

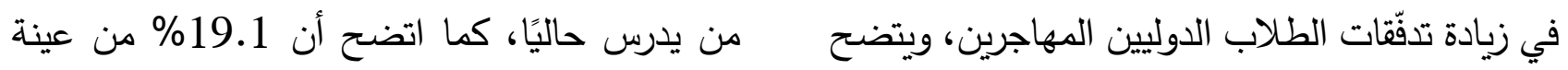
ذلك جليَّا بتفحّص إجابات أفراد عينة الدراسة، حيث الدراسة سبق أن درس أحد أفراد أسرته بالمملكة العربية إن ثلثي العينة سمّل لهم أقاربهم وأصدقاؤهم الحصول السعودية؛ وهنا يظهر دور الثبكات الاجتماعية. على المنحة الدراسية في المملكة العربية السعودية. 
جدول (8): من سهّل على الطالب الحصول على المنحة الدراسية.

\begin{tabular}{|c|c|c|}
\hline النسبة \% & التكرار & سهّل \\
\hline 19.1 & 62 & مؤسسة \\
\hline 29 & 94 & أقارب \\
\hline 37 & 120 & أصدقاء \\
\hline 14.8 & 48 & بصفة شخصية \\
\hline 100 & 324 & الإجمالي \\
\hline
\end{tabular}

جدول (9): وجود أقارب أو أحد أفراد الأسرة يدرس حاليًا في المملكة.

\begin{tabular}{|c|c|c|}
\hline النسبة \% & التكرار & غيرك \\
\hline 19.8 & 64 & نعم \\
\hline 80.2 & 260 & $\gamma$ \\
\hline 100 & 324 & الإجمالي \\
\hline
\end{tabular}

جدول (10): وجود أقارب أو أحد أفراد الأسرة قد درس سابقًا في المملكة.

\begin{tabular}{|c|c|c|}
\hline النسبة \% & التكرار & سبق \\
\hline 19.1 & 62 & نعم \\
\hline 80.9 & 262 & ע \\
\hline 100 & 324 & الإجمالي \\
\hline
\end{tabular}

جامعة الإمام محمد بن سعود الإسلامية، بوصفها الطلاب الدوليين؛ لاتخاذ قرار سفرهم واختيارهم لهذه المؤسسة التعليمية. ومع تعدّد الجامعات السعودية لتهبية وجهة تعليمية مفضّلة: للمؤسسات التعليمية دور مؤثر في اختيار الطلاب وتنوّعها بشكل عام، وجامعات منطقة الرياض بشكل الدوليين لوجهتهم، وتختلف أسباب التفضيل وتتنوّع من خاص؛ لكن أفراد عينة الدراسة قد اختاروا جامعة شخص لآخر، فبعضهم يرجع اختياره إلى السمعة الإمام محمد بن سعود الإسلامية دون غيرها من فئن

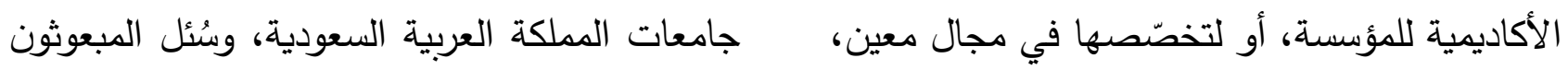

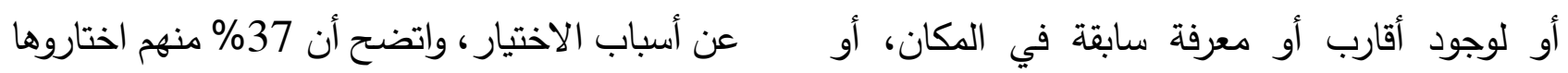

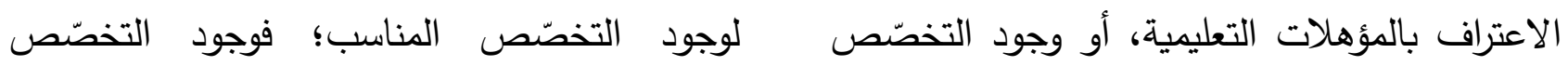

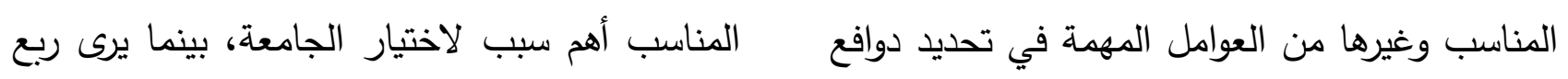


أفراد العينة أن سبب اختيارهم لوجود أقارب وأصدقاء، مميّزة، وقد يعود ذلك إلى الجهود المبذولة من قِبل وهذا متوقّع لأن ثلثي العينة سهّل لهم أقاربهم الجامعة في خدمة طلاب المنح، إضافة إلى مزايا المنحة التعليمية، التي راعت طلاب المنح من حيث: وأصدقاؤهم الحصول على المنح الدراسية.

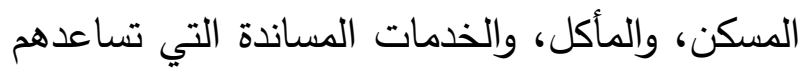
على التنرّز للدراسة والتركيز بها.

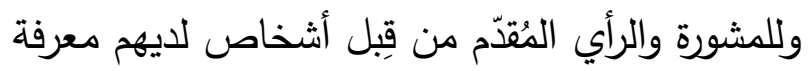
عن الجامعة دور بارز ومهّم في استقطاب طلاب المنح إلى الجامعة مستقبلًا؛ ولذلك ضُمّنت استمارة

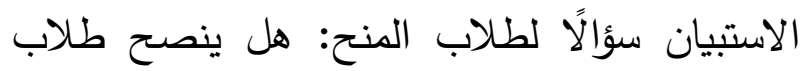
دولته بالدراسة في جامعة الإمام محمد بن سعود

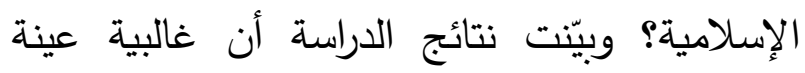
الدراسة 93.2\% ينصحون بالجامعة، وهذا مصدر قوة للجامعة؛ حيث إن طلابها وخِّرِيهِا أفضل مُسوّقين

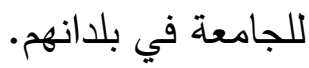

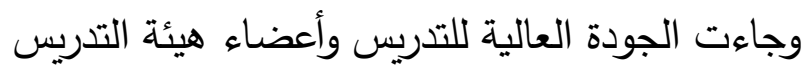
ثالثًا بنسبة 15.4\%، ثم من لم يجد قبولًا في غيرها بنسبة 10.5\%، وتلا ذلك من اختارها؛ لكونها جامعة إسلامية عريقة بنسبة 9.3\%، وأخيرًا من اختارها لأسباب أخرى بنسبة 1.9\% ووجهة نظر الطلاب عن تقييم تجربتهم لجامعة الإمام محمد بن سعود الإسلامية مهمة لمسؤولي برنامج

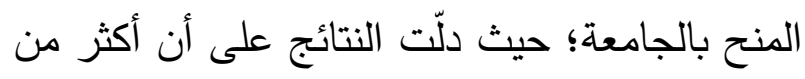
نصف عينة الدراسة 55.6\% يقيّمون تجربتهم بالممتازة، ويُقيّم 31.5\% تجربتهم بالجيدة، بينما يرى

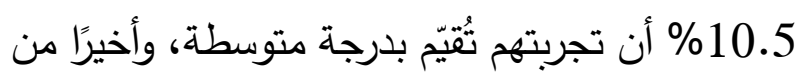
قيّ تجربته بالمقبولة بنسبة 2.5\% من عينة الدراسة.

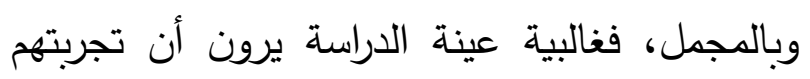

\begin{tabular}{|c|c|c|}
\hline & 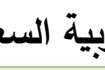 & \\
\hline النسبة \% & التكرار & اختيار \\
\hline 25.9 & 84 & وجود أقارب وأصدقاء \\
\hline 37 & 120 & وجود التخصّص المناسب \\
\hline 15.4 & 50 & الجودة العالية للتدريس وأعضاء هيئة التدريس \\
\hline 10.5 & 34 & لم أجد قبولًا في غيرها \\
\hline 1.9 & 6 & أخرى \\
\hline 9.3 & 30 & لكونها جامعة إسلامية عريقة \\
\hline 100 & 324 & الإجمالي \\
\hline
\end{tabular}




$$
\text { علي معيض أحمد محمد القرني }
$$

جدول (12): تقييم طالب المنحة تجربة الاراسة بجامعة الإمام محمد بن سعود الإسلامية.

\begin{tabular}{|c|c|c|}
\hline 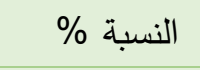 & التكرار & تقييم \\
\hline 55.6 & 180 & 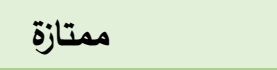 \\
\hline 31.5 & 102 & جيدة \\
\hline 10.5 & 34 & متوسطة \\
\hline 2.5 & 8 & مقبولة \\
\hline 100 & 324 & 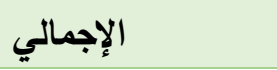 \\
\hline \multicolumn{3}{|c|}{ جدول (13): توصيّة طالب المنحة طلاب بلده بالدراسة في جامعة الإمام محمد بن سعود الإسلامية بالمملكة. } \\
\hline 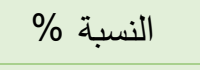 & التكرار & تنصح \\
\hline 93.2 & 302 & نعم \\
\hline 6.8 & 22 & ע \\
\hline 100 & 324 & الإجمالي \\
\hline
\end{tabular}

تحقيق الهدف من الهجرة (النوايا المستقبلية): هجرة طلاب المنح إلى المملكة مؤقتة محدودة المدة

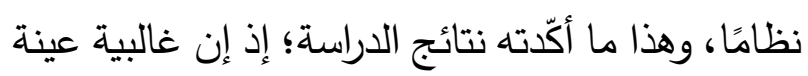
الدراسة ينوي العودة إلى بلده فور الانتهاء من الدراسة بنسبة 85.8\%. وتحدّد ضوابط قبول طلاب المنح الدراسية لغير السعوديين أنه يتحتّم على طالب المنح الدراسية أن يُغادر بعد انتهاء مدة دراسته خلال مدة لا لانيل تتجاوز ثلاثة أشهر فور انتهائها.

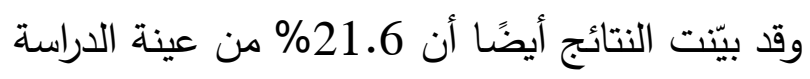
يرغبون في الحصول على فرصة للإقامة الدائمة في

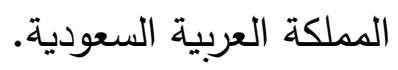

وتُشنير الإحصاءات والبيانات إلى وجود اتجاه واضح

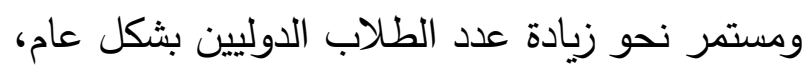

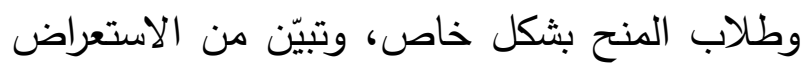

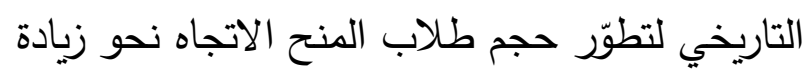
عددهم تاريخيًّا، ومن المتوقِّع أن يزداد عددهم مستقبلًا.

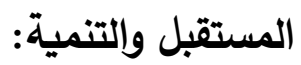
تبتعث الدول طلابها للدراسة في الخارج؛ رغبة منها في أن يساهموا بعد عودتهم في نهضة بلدانهم، ونقل

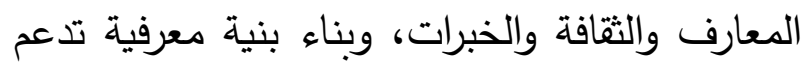
التتمية بها. وتُقدّم المملكة العربية السعودية منحًا دراسية إلى أبناء الأمة العربية والإسلامية والدول

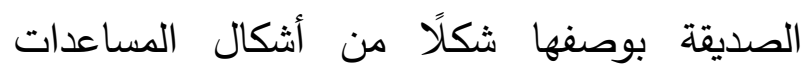
التتموية، وتحفّز هذه الميزة بعض البلدان لإرسال

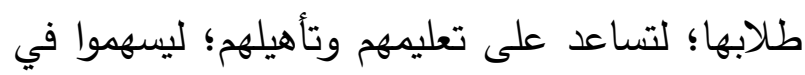
دفع عجلة التتمية والتقدّم ببلادهم، وليُطبّبّوا ما تعلموه من العلوم النافعة بعد عودتهم. وبيؤال أفراد عينة الدراسة عن دور خِرّيجي جامعة الإمام محمد بن سعود

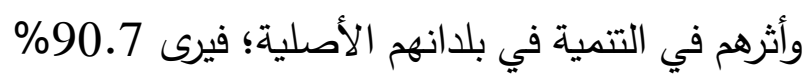

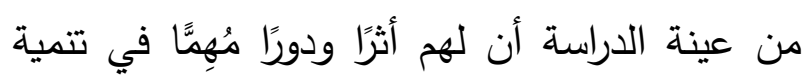

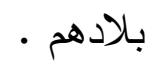


وكان من الضروري إتاحة الفرصة لأفراد العينة طلاب المنح في المملكة، ويتضح أن أكثر من ثلاثة لإيضاح وجهة نظرهم، وانطباعاتهم عن مستقبل أرباع عينة الدراسة يرون زيادة عددهم مستقبلًا. جدول (14): دور خِّرّجي طلاب منح جامعة الإمام في تنمية بلدانهم.

\begin{tabular}{|c|c|c|}
\hline 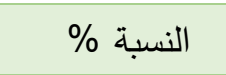 & التكرار & تنمية \\
\hline 90.7 & 294 & نعم \\
\hline 9.3 & 30 & ע \\
\hline 100 & 324 & الإجمالي \\
\hline \multicolumn{3}{|c|}{ جدول (15): دور خِريجي طلاب منح جامعة الإمام في تنمية بلدانهم. } \\
\hline 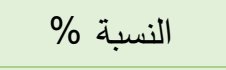 & التكرار & هدف \\
\hline 14.2 & 46 & تبقى في المملكة ت \\
\hline 85.8 & 278 & تعود إلى بلدك \\
\hline 100 & 324 & 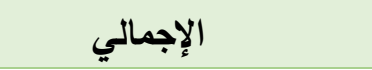 \\
\hline \multicolumn{3}{|c|}{ جدول (16): الرغبة في الحصول على فرصة الإقامة الدائمة بالمملكة. } \\
\hline 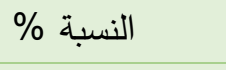 & التكرار & إقامة دائمة \\
\hline 21.6 & 70 & نعم \\
\hline 78.4 & 254 & ע \\
\hline 100 & 324 & الإجمالي \\
\hline \multicolumn{3}{|c|}{ جدول (17): وجهة نظر طلاب المنح لمستقبل طلاب المنح بالجامعة. } \\
\hline 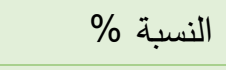 & التكرار & مستقبل \\
\hline 78.4 & 254 & زيادة عددهم \\
\hline 8 & 26 & انخفاض عددهم \\
\hline 13.6 & 44 & البقاء على الوضع الحالي \\
\hline 100 & 324 & الإجمالي \\
\hline
\end{tabular}

الجامعي 1441هـ؛ يتضح أن مجموع المستفيدين قد بلغ نحو (59145) طالبًا وطالبة من طلاب المنح.

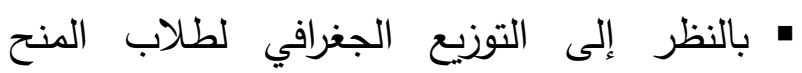

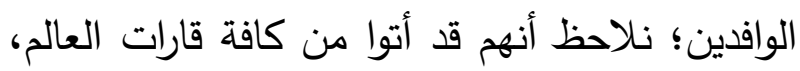

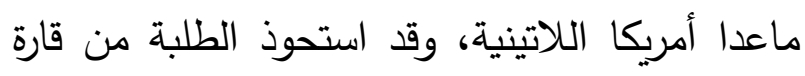

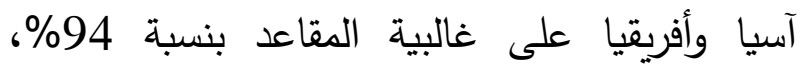

\section{الخاتمة والتوصيات}

من أهم النتائج التي توصّلت إليها الدراسة:

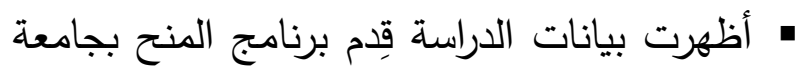
الإمام محمد بن سعود الإسلامية منذ سنوات نثأتها الأولى. ومن خلال التتبع للمستفيدين من برنامج المنح من العام الجامعي 1396هـ- Уوب أهـ، وحتى العام 
85.8\%؛ ويدّّ هذا على أن هجرة طلاب المنح هجرة

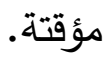
• دلّت النتائج على أن أكثر من نصف عينة الدراسة 55.6، يُقيّمون تجربة دراستهم عن جامعة الإمام محمد بن سعود الإسلامية بالممتازة.

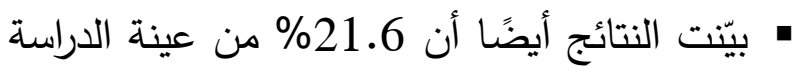
يرغبون في الحصول على فرصة للإقامة الدائمة بالمملكة العربية السعودية.

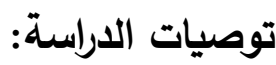
بناء على نتائج الدراسة التي تُوصّل إليها؛ فان الباحث

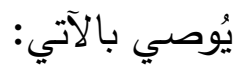
1- أهمية إجراء دراسات وبحوث دورية ومستمرة في مجال الطلاب الدوليين، وحثّ الباحثين وتثجيعهم دراء على إجراء المزيد من الدراسات الجغرافية حول هجرة الطلاب الدوليين - حسب الجنسيات- إلى المملكة

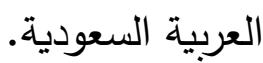
2- إنثاء وحدة متابعة لطلاب المنح بعد التخرّج، والتواصل معهم، وإمكانية الاستفادة منهم في بلدانهم

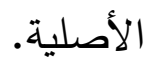
3- يعدّ التتقل الجغرافي في حدّ ذاته شكلًا من أشكال

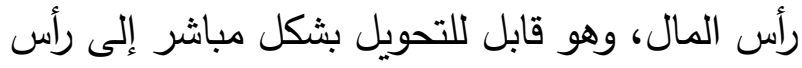
مال اقتصادي، مع التحاق الخِرِّين الدوليين بالعمل، وتعدّ المملكة العربية السعودية من أكبر البلدان الجاذبة

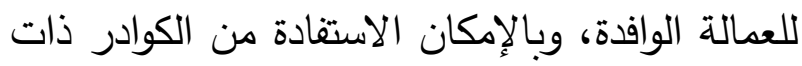
الكفاءات العالية من طلاب المنح في سوق العمل؛
ويتضح أيضًا أن ثلثي طلاب المنح الوافدين وفدوا من

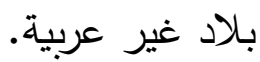
- أظهرت نتائج الدراسة أن غالبية أفراد العينة ملتحقون ببرامج البكالوريوس بنسبة 77.2\%، وينتمي غالبيتهم إلى كليتي الشريعة وأصول الدين المتخصّصة في العلوم الثرعية بنسبة 61.8\%. - بيّنت الدراسة أن أفراد العينة يرون أن أهم أسباب لهب تفضيلهم للدراسة في المملكة العربية السعودية يتمثّل في: وجود برامج المنح الدراسية اليُقدّة للطلاب الأجانب بجامعات المملكة العربية السعودية، وهو من أهم برامج الاستقطاب؛ لتعدد مزاياه ومنافعه. ومع أن 59.3 من أفراد العينة حصلوا على فرصة لإكمال تعليمهم في بلدانهم الأصلية؛ لكنهم اختاروا الدراسة

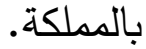
• بيّنت النتائج أن قُرابة ثلثي عينة الدراسة سهّل لهم أقاربهم وأصدقاؤهم الحصول على المنحة الدراسية في المملكة العربية السعودية؛ ويظهر هنا دور الشبكات الاجتماعية وتأثيرها، فهي أحد عوامل الجذب الرئيسة.

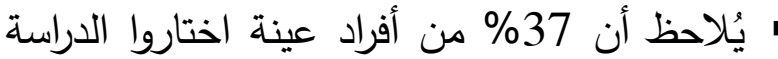
بجامعة الإمام محمد بن سعود الإسلامية من بين الجامعات السعودية؛ لوجود التخصّص المناسب. • يرى 90.7\% من عينة الدراسة أن لخِريجي جامعة

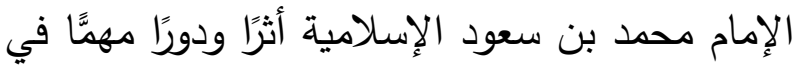
تنمية بلادهم الأصلية. • أكّدت نتائج الدراسة أن غالبية عينة الدراسة ينون العودة إلى بلدانهم فور الانتهاء من الدراسة بنسبة 
مجلة الجوف للعلوم الاجتماعية. 2014، 1(1)، ص . .120-95.

السميح، عبد المحسن بن محمد. (2004م). الصعوبات التعليمية والإدارية لطلاب الدنح الدراسية: دراسة ميدانية على طلاب المنح الدراسية بجامعة الإمام محمد بن سعود الإسلامية. مجلة جامعة الإمام محد بن سعود الإسلامية، (41)، ص 520-598. الصبيحي، محمد بن سليمان. (1422هـ). تعليم أبناء المسلمين في عهر خادم الحرمين الثرفين: تجربة مانية جامعة الإمام محمد بن سعود الإسلامية في الفترة من 1402-1422هـ. الندوة العالمية عن جهود خادم الحرمين الشريفين في خدمة الإسلام والمسلمين.

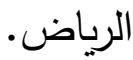

الطائي، إيمان حسين. (2012م). كيف نحدد حجم العينة. (نسخة إلكترونية). http://www.cope.uobaghdad.edu.iq/uploads/art icles/eman $20 \%$ husain/\%D8AD\%D\%8AC\%D9 $\% 20 \% 85 \% \mathrm{D} \% 8 \mathrm{~A} \% 7 \mathrm{D} \% 84 \% 9 \mathrm{D} \% 8 \mathrm{~B} \% 9 \mathrm{D} \% 9$ 8A\%D86\%9D\%8A9.docx

العيسوي، فايز محمد. (2005م). أسس جغرافية السكان. الإسكندرية: دار المعرفة الجامعية. فايد، فريد علي محمد. (2014م). فاعلية الممارسة

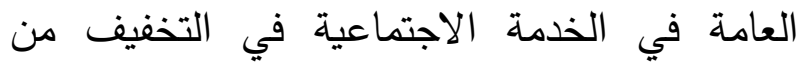
الضغوط الحياتية لدى طلاب المنح الدراسية. مجلة الخدمة الاجتماعية: الجمعية المصرية للأخصائيين الاجتماعيين، (52)، ص 405 - 454. القرني، حسن بن عبدالله (2018م). بعض مشكلات طلاب المنح الدراسية بجامعة تبوك والآليات الإجرائية
مما سيُعزّز الاقتصاد الوطني، والمساهمة في جذب

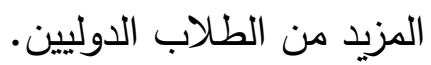
4- في ظلّ التوجّه الحالي إلى تطوير مصادر

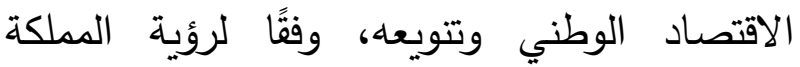
2030م، وما تم من خطوات إجرائية واستقلال ثلاث جامعات؛ فإن الطلاب الدوليين يُمتّلون أحد مصادر

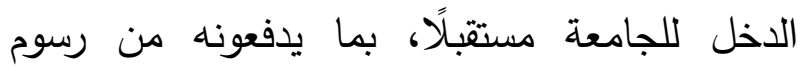
الدراسية كل عام إضافة إلى الإسكان والخدمات

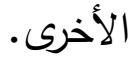

5- بالنظر إلى التوزيع الجغرافي لطلاب المنح؛

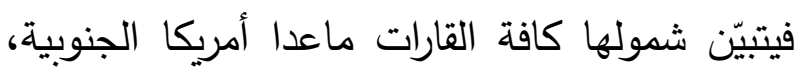

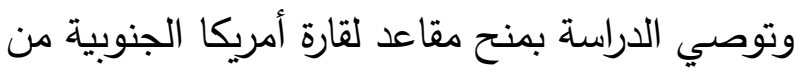
خلال البعثات الدبلوماسية بدول القارة.

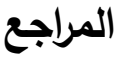

أبا الخيل، عبدالوهاب بن محمد. (2009م). استخدام الطلاب الأجانب المكتبات الجامعية: دراسة واقع بن مكتبة الأمير سلمان المركزية بجامعة الملك سعود. مجلة جامعة الملك سعود - الآداب. مج 21. ع ع 1. 1.

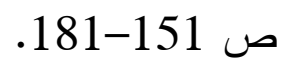

جامعة الإمام محمد بن سعود الإسلامية. (2019م).قاعدة بيانات طلاب المنح الدراسية للفصل الدراسي الأول للعام الجامعي 1441هـ.عمادة شؤون

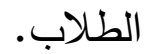

الرويلي، نواف بن عبدالله. (2014). واقع التعليم الجامعي وتحديّاته في بعض الجامعات السعودية من وجهة نظر أعضاء هيئة التدريس: دراسة ميدانية. 


$$
\text { علي معيض أحمد محمد القرني }
$$

Abbott, A. and Silles, M. (2016), Determinants of International Student Migration. World Econ, 39: 621-635. doi:10.1111/twec.12319 Ahmad, Syed \& Buchanan, F. Robert \& Ahmad, Norita. (2016). Examination of students' selection criteria for international education. International Journal of Educational Management. 30. 1103-1088. 10.1108/IJEM.0145-2014-11

Basford, Scott Eric, "International Student Migration for Development: An Institutional Approach to the Norwegian Quota Scheme. " Master's Thesis, University of Tennessee, 2014. http://trace.tennessee.edu/utk_gradthes/3139

Beech, S. E. 2015. "International Student Mobility: The Role of Social Networks." Social and Cultural Geography 16 (3): 332-350. doi: 14649365.2014.983961/10.1080

ICEF Monitor. 2015 The State of International Student Mobility in 2015. ICEF, Bonn. Available from http://monitor.icef. com/2015/11/the-state-of-internationalstudent-mobility-in-2015/.

International Student Migration for Development: An Institutional Approach to the Norwegian Quota Scheme A Thesis Presented for the Master of Science Degree The University of Tennessee, Knoxville

King, R., and Raghuram, P. 2013. "International Student Migration: Mapping the Field and New Research Agendas." Population, Space and Place, 19(2): 127-137.

Lee, Everett .S. 1966: "A theory of migration", Demography, Vol. 3, No. 1, 47-57

She, Q., \& Wotherspoon, T. (2013). International student mobility and highly skilled migration: a comparative study of Canada, the United States, and the United Kingdom. SpringerPlus, 2(1), 132. https://doi.org/10.1186/2193-1801-2-132

Stuart Anderson. the importance of international students to America, JULY 2013; also available at www.nfap.com

Suzanne E. Beech (2015) International student mobility: the role of social networks, Social \&

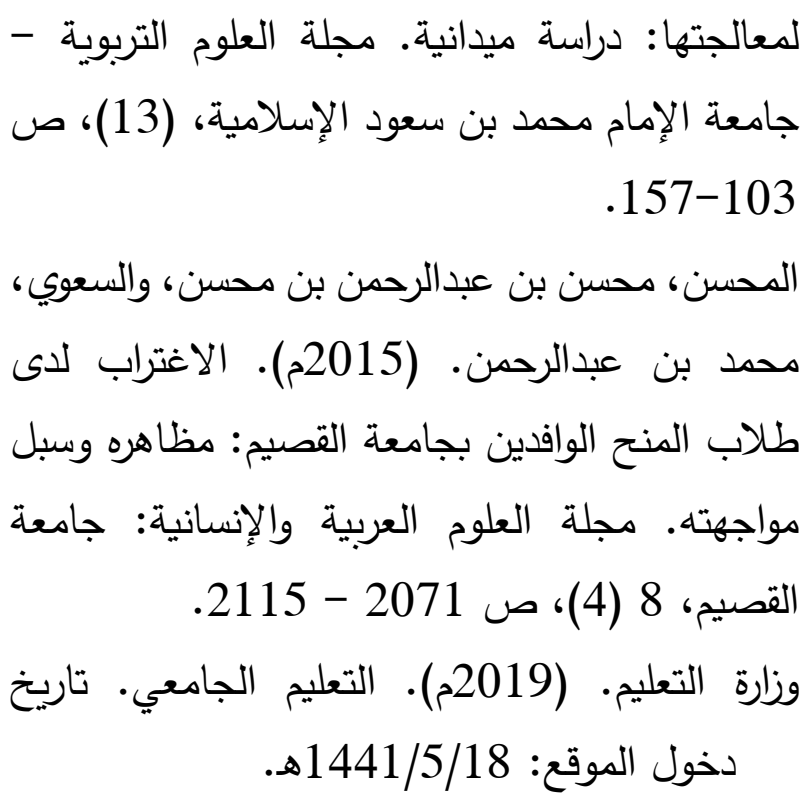

https:/www.moe.gov.sa/ar/HighEducation/Sc holarships_for_non_Saudis/Pages/default.a $\underline{\mathrm{spx}}$

وزارة التعليم. (2018م). قاعدة بيانات إحصائيات

التعليم العالي. تاريخ دخول الموقع: 1440/10/8 هـ

https://departments.moe.gov.sa/PlanningDevel opment/RelatedDepartments/Educationstati sticscenter/EducationDetailedReports/Page s/default.aspx

وزارة المالية. (2020م). المكتبة الرقمية (بيانات

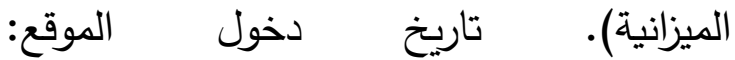

1441/12/28 هـ.

https://www.mof.gov.sa/docslibrary/Budget/Pa ges/default.aspx اليونسكو. (2015م). معهد اليونسكو للإحصاء. تاريخ دخول الموقع: 1441/5/18هـ. http://uis.unesco.org/en/glossaryterm/international-or-internationally-mobile$\underline{\text { students }}$ 
2020), Studies in Higher Education, 42:5, 825832, DOI: $10.1080 / 03075079.2017 .1293872$

Middlehurst, Robin. (2018). Leadership of Internationalization in Higher Education Institutions.
Cultural Geography, 16:3, 332-350, DOI: 10.1080/14649365.2014.983961

Rahul Choudaha (2017) Three waves of international student mobility (1999- 


\title{
Expatriate students' scholarship at Imam Muhammad Ibn Saud Islamic University (Population Geography Study)
}

\author{
Ali bin Moaid Ahmed Al-Qarni \\ Assistant Professor / Population Geography / Department of Geography / College of Social \\ Sciences Imam Muhammad bin Saud Islamic University
}

\begin{abstract}
Expatriate students studying outside their countries has increased recently, which leads to increase the interest in trying to understand and explain their migration, the factors affecting the decision of the Expatriate students for studying outside their countries, and what their future directions. Nowadays, Expatriate students represent an important part of immigration. The scholarship program is one of the most important programs at Imam Muhammad bin Saud Islamic University. In this study, the historical development of the numbers of Expatriate students' scholarship at Imam Muhammad bin Saud Islamic University, the geographical distribution of the scholarship students' countries, the demographic, students social and economic characteristics, and what are the future trends of the Expatriate students' scholarship were discussed. The study is based on the descriptive analytical approach. A questionnaire was designed and distributed to a sample of Expatriate scholarship students consisted of 324 students.

The results showed that: Two-thirds of the Expatriate scholarship students came from non-Arab countries, and $61.8 \%$ of them are studying forensic sciences. One of the main reasons why the students prefer to study in the Kingdom of Saudi Arabia is the scholarship programs for Expatriate students. The study also revealed the role of social networks in the decision to choose the university in addition to the presence of the appropriate specialization.

Keywords: Expatriate Students, Scholarship Students, Immigration, Imam Mohammed Bin Saud Islamic University and Population Geography.
\end{abstract}

